\title{
Epigenetic alterations in the lateral amygdala are required for reconsolidation of a Pavlovian fear memory
}

\author{
Stephanie A. Maddox ${ }^{1}$ and Glenn E. Schafe ${ }^{1,2,3}$ \\ ${ }^{1}$ Department of Psychology, Yale University, New Haven, Connecticut 06520, USA; ${ }^{2}$ Interdepartmental Neuroscience Program, \\ Yale University, New Haven, Connecticut 06520, USA
}

\begin{abstract}
Epigenetic mechanisms have been widely implicated in synaptic plasticity and in memory consolidation, yet little is known about the role of epigenetic mechanisms in memory reconsolidation processes. In the present study, we systematically examine the role of histone acetylation and DNA methylation in the reconsolidation of an amygdala-dependent Pavlovian fear memory. We first show that the acetylation of histone $3(\mathrm{H} 3)$, but not histone 4 (H4), is regulated following auditory fear memory retrieval in the lateral nucleus of the amygdala (LA). We next show that histone deacetylase (HDAC) inhibition in the LA enhances both retrieval-induced histone acetylation and reconsolidation of an auditory fear memory. Conversely, inhibition of DNA methytransferase (DNMT) activity in the LA significantly impairs both retrieval-related H3 acetylation and fear memory reconsolidation. The effects of HDAC and DNMT inhibitors on fear memory reconsolidation were observed to be time-limited and were not evident in the absence of memory reactivation. Further, memories lost following DNMT inhibition were not observed to be vulnerable to spontaneous recovery, reinstatement, or to a shift in testing context, suggesting that memory impairment was not the result of facilitated extinction. Finally, pretreatment with the HDAC inhibitor was observed to rescue the reconsolidation deficit induced by the DNMT inhibitor. These findings collectively suggest that histone acetylation and DNA methylation are critical for reconsolidation of fear memories in the LA.
\end{abstract}

Considerable progress has been made in defining the cellular and molecular mechanisms underlying memory "reconsolidation" in the mammalian brain (Dudai and Eisenberg 2004; Tronson and Taylor 2007). With notable exceptions (Alberini 2005), findings have collectively suggested that reconsolidation shares many of the core molecular features with that of initial memory consolidation, including NMDA-receptor (NMDAR)driven activation of protein kinase signaling cascades (Duvarci et al. 2005; Ben Mamou et al. 2006; Tronson et al. 2006; Milton et al. 2008), the involvement of transcription factors (Kida et al. 2002), de novo mRNA and protein synthesis (Nader et al. 2000; Da Silva et al. 2008; Duvarci et al. 2008), and the involvement of immediate early genes (Lee et al. 2005; Maddox and Schafe 2011; Maddox et al. 2011).

While the importance of de novo transcription in memory reconsolidation has been well established (Nader et al. 2000; Kida et al. 2002; Da Silva et al. 2008; Duvarci et al. 2008; but see Parsons et al. 2006), relatively little is known about the mechanisms that regulate transcriptional access during memory reconsolidation. Recent studies, for example, have highlighted the importance of epigenetic mechanisms, including alterations in chromatin structure and DNA methylation, in memory consolidation processes (Levenson and Sweatt 2005, 2006; Barrett and Wood 2008; Jiang et al. 2008). Chromatin, which consists of DNA packaged tightly around a core of eight histones, is known to be post-translationally regulated by acetylation of histones on their N-terminal tails via histone acetyltransferases (HATs). This process causes chromatin structure to relax, leading to enhanced transcription, and can be reversed by histone deacetylases (HDACs) (Varga-Weisz and Becker 1998; Turner 2002; Yang

\footnotetext{
${ }^{3}$ Corresponding author.

E-mail glenn.schafe@yale.edu.

Article is online at http://www.learnmem.org/cgi/doi/10.1101//m.2243411.
}

and Seto 2007). In contrast, DNA methylation has been associated with transcriptional repression (Levenson and Sweatt 2005; Miller and Sweatt 2007; Miller et al. 2008), a process which is catalyzed by DNA methyltransferases (DNMTs) (Miller and Sweatt 2007; Miller et al. 2008).

Both histone acetylation and DNA methylation have been widely implicated in hippocampal- and, more recently, amygdaladependent memory formation. Contextual fear conditioning, for example, has been shown to increase acetylation of histone $\mathrm{H} 3$ in the hippocampus (Levenson et al. 2004; Vecsey et al. 2007; Miller et al. 2008), and inhibition of HDAC activity enhances hippocampal-dependent memory formation, including object recognition (Stefanko et al. 2009) and contextual fear memory (Levenson et al. 2004). Similarly, auditory fear conditioning enhances histone $\mathrm{H} 3$ acetylation in the lateral amygdala (LA) (Monsey et al. 2011), while either systemic administration (Bredy and Barad 2008) or intra-LA infusion (Monsey et al. 2011) of an HDAC inhibitor enhances fear memory consolidation. Conversely, inhibition of DNMT activity has been shown to impair hippocampal- and amygdala-dependent memory formation, including contextual and auditory fear conditioning, cocaine-induced conditioned place preference, and spatial learning (Lubin et al. 2008; Miller et al. 2008; Feng et al. 2010; Han et al. 2010; Monsey et al. 2011).

While studies have pointed to a clear and vital role for epigenetic alterations in memory consolidation processes, little is known about the role of epigenetic mechanisms in memory reconsolidation. A recent study showed that the nuclear transcription factor NF-кB regulates contextual fear memory reconsolidation via alterations in chromatin structure in the hippocampus (Lubin and Sweatt 2007), suggesting that epigenetic alterations may play a critical role in memory reconsolidation. In the present study, we examined the role of histone acetylation and DNA methylation in the reconsolidation of an amygdala-dependent auditory Pavlovian fear memory. We show that retrieval of an 
auditory fear memory regulates histone acetylation in the lateral nucleus of the amygdala (LA) and that intra-LA infusion of inhibitors to HDAC and DNMT activity enhances or impairs fear memory reconsolidation, respectively.

\section{Results}

\section{Retrieval of an auditory fear memory regulates acetylation of histone $\mathrm{H} 3$ in the LA}

While numerous studies have shown that histone acetylation is regulated by memory formation (Levenson et al. 2004; Miller et al. 2008; Zhao et al. 2010; Monsey et al. 2011), few studies have examined the regulation of histones following memory retrieval. A relatively recent study showed that histone $\mathrm{H} 3$ acetylation is regulated in area CA1 of the hippocampus during retrieval of a contextual fear memory (Lubin and Sweatt 2007). However, no study to date has examined alterations in histone acetylation within the amygdala following fear memory retrieval. In our first series of experiments, we therefore examined the time course of histone $\mathrm{H} 3$ and $\mathrm{H} 4$ acetylation in the LA following auditory fear memory retrieval (Fig. 1A). Rats underwent auditory fear conditioning, followed $24 \mathrm{~h}$ later by either a tone reactivation trial (reactivated), or a no-reactivation trial in which they were placed in the reactivation chamber but not presented with a tone (nonreactivated). Rats were sacrificed at 60, 90, or $120 \mathrm{~min}$ after reactivation or no-reactivation sessions. A group of naive rats was handled and habituated but did not undergo conditioning or memory reactivation (naive). Analysis of the behavioral data (preCS vs. CS freezing) (Fig. 1B) revealed that each group exhibited significant memory retrieval during the reactivation trial [60 min: $t_{(6)}=19.45, P<0.01 ; 90 \mathrm{~min}: t_{(8)}=20.69, P<$ $\left.0.01 ; 120 \mathrm{~min}: t_{(5)}=18.57, P<0.01\right]$, while no significant memory retrieval was observed during the nonreactivation trial [60 min: $t_{(6)}=0.35 ; 90 \mathrm{~min}: t_{(5)}=0.30 ; 120 \mathrm{~min}: t_{(6)}=0.09$ ]. Further, an ANOVA comparing the freezing scores between each of the three groups during the reactivation trial revealed no significant difference in the amount of memory retrieval, $F_{(2,19)}=0.23$.

Analysis of the $60 \mathrm{~min}$ time point revealed no significant difference in the level of histone $\mathrm{H} 3\left(\mathrm{AcH} 3 ; F_{(2,19)}=0.01\right)$ or $\mathrm{H} 4$ (AcH4; $F_{(2,19)}=0.02$ ) (Fig. 1C) acetylation between the groups. Moreover, no difference was observed between groups in the total protein levels of histone $\mathrm{H} 3\left(\mathrm{tH} 3 ; F_{(2,19)}=0.17\right)$ or $\mathrm{H} 4$ ( $\mathrm{tH} 4$; $\left.F_{(2,19)}=0.09\right)$ (Fig. 1D). Further, no difference was observed between the groups in the levels of the loading control GAPDH $\left(F_{(2,19)}=0.20\right)$ (data not shown).

In contrast to the 60-min group, the 90-min group exhibited a significant increase in the acetylation of histone $\mathrm{H} 3\left(F_{(2,20)}=\right.$ 5.39, $P<0.01)$, but not H4 $\left(F_{(2,20)}=0.12\right)$ (Fig. 1E), following memory retrieval. Duncan's post-hoc tests revealed that the reactivated group was significantly different from both naive and nonreactivated groups $(P<0.05)$, while no significant difference between naive and nonreactivated groups was observed $(P>$ 0.05). Analysis of total $\mathrm{H} 3 / \mathrm{H} 490 \mathrm{~min}$ following the reactivation session found no significant difference in either total H3 $\left(F_{(2,20)}=0.06\right)$ or total H4 $\left(F_{(2,20)}=0.1\right)$ (Fig. 1F). Further, no difference was observed between the groups in the levels of the loading control GAPDH $\left(F_{(2,20)}=0.17\right)$ (data not shown).

At the 120-min time point, we observed no differences between groups in AcH3 $\left(F_{(2,18)}=0.01\right)$, AcH4 $\left(F_{(2,18)}=0.05\right)$ (Fig. 1G), or in total levels of H3 $\left(F_{(2,18)}=0.001\right)$ or $\mathrm{H} 4\left(F_{(2,18)}=\right.$ 0.05) (Fig. 1H). Further, no difference was observed between the groups in the levels of the loading control GAPDH $\left(F_{(2,18)}=\right.$ 2.47) (data not shown).

In an additional experiment (Fig. 2), we examined whether the acetylation of histone H3 in the LA is specific to fear memory retrieval rather than to exposure to tone alone. Rats underwent either auditory fear-conditioning (reactivated) or two presentations of the tone alone (tone alone) in Chamber A. The next day, rats in both groups were placed into Chamber B and given a single tone presentation. As before, a third group of rats was handled and habituated but did not undergo conditioning or memory reactivation (naive). Analysis of the behavioral data (preCS vs. CS freezing) revealed that the reactivated group exhibited significant memory retrieval during the reactivation trial $\left(t_{(6)}=41.51, P<0.01\right)$, while no significant increase in freezing was observed for the tone alone group $\left(t_{(6)}=0.10\right)$ (Fig. 2B). Western blotting revealed a significant regulation of $\mathrm{AcH} 3$ protein within the LA $\left(F_{(2,16)}=6.69, P<0.05\right)$ (Fig. $\left.2 \mathrm{C}\right)$. Duncan's posthoc tests revealed a significant difference between the reactivated group and the tone alone and naive groups $(P<0.05)$, while no significant difference between naive and tone alone groups was observed $(P>0.05)$. No difference was observed between the levels of total $\mathrm{H} 3\left(F_{(2,16)}=0.02, P>0.05\right)$ or in the loading control $\operatorname{GAPDH}\left(F_{(2,16)}=1.43\right)$.

Thus, retrieval of an auditory fear memory promotes an increase in the acetylation of histone H3 in the LA at 90 min following memory retrieval. This effect is specific to fear memories that are actively retrieved; at no time point examined was the acetylation of histone $\mathrm{H} 3$ for the nonreactivated group different from naive controls. Further, this effect is not attributable to exposure to the retrieval context alone or to presentation of the tone alone.

\section{Inhibition of histone deacetylase activity in the LA enhances auditory fear memory reconsolidation}

Previous studies have shown that inhibition of histone deacetylase activity enhances memory in a variety of paradigms, including contextual and auditory fear conditioning, object recognition, and spatial memory (Vecsey et al. 2007; Bredy and Barad 2008; Guan et al. 2009; Zhao et al. 2010; Monsey et al. 2011). Further, a recent study showed that systemic injection of the HDAC inhibitor, valproic acid, prior to fear memory retrieval enhances subsequent recall of an auditory fear memory (Bredy and Barad 2008). Here, we used local infusion of an HDAC inhibitor in the LA to systematically examine whether histone acetylation regulates auditory fear memory reconsolidation.

\section{HDAC inhibition increases histone acetylation in the LA following auditory fear memory retrieval}

In our first experiment, we determined whether intra-LA infusion of trichostatin A (TSA) results in enhanced histone acetylation in the LA following retrieval of an auditory fear memory. Rats were trained with two tone-shock pairings in Chamber A. Twenty-four hours later, rats received a memory reactivation trial in Chamber B followed $1 \mathrm{~h}$ later by intra-LA infusion of vehicle $(0.5 \mu \mathrm{L} /$ side $)$ or TSA $(1 \mu \mathrm{g} /$ side $)$. Rats were then sacrificed $30 \mathrm{~min}$ following infusion $(90 \mathrm{~min}$ following memory reactivation), and punches from the LA were taken and processed using Western blotting (Fig. 3A). Analysis of the behavioral data (preCS vs. CS freezing) for the vehicle- and TSA-infused groups revealed a main effect of trial $\left(F_{(1,10)}=636.27, P<0.05\right)$ but no significant effect of group $\left(F_{(1,10)}=0.01\right)$, indicating that both groups exhibited significant and equivalent memory retrieval during the reactivation trial (Fig. 3B). Intra-LA infusion of TSA following fear memory retrieval resulted in enhanced acetylation of histone $\mathrm{H} 3\left(t_{(10)}=4.21, P<0.05\right)$ and $\mathrm{H} 4\left(t_{(10)}=3.51\right.$, $P<0.05)$ relative to vehicle-infused controls (Fig. 3C, left). Moreover, no differences were observed in total protein levels of 

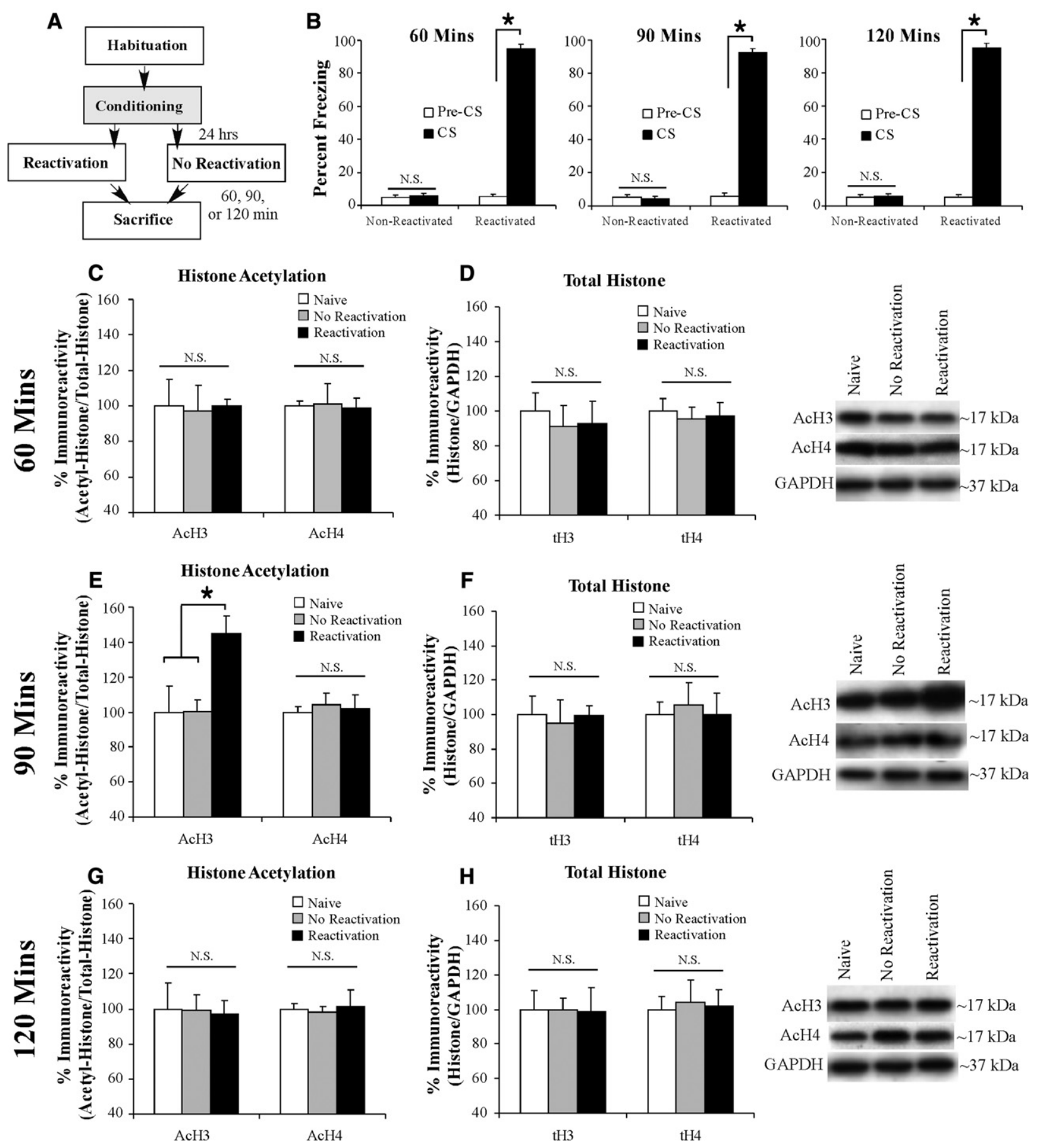

Figure 1. Auditory fear memory retrieval transiently regulates histone $\mathrm{H} 3$ acetylation in the LA. $(A)$ Schematic of the behavioral protocol. Rats were handled and habituated to both the training and testing context for $4 \mathrm{~d}$ prior to fear conditioning. Twenty-four hours following training, rats were given either a reactivation or no-reactivation session and were sacrificed 60, 90, or 120 min later. (B) Memory retrieval data for the $60-$, $90-$, and 120-min groups during the no-reactivation and reactivation trials. ${ }^{*} P<0.05$ relative to the preCS period. (C) Western blot analysis of acetylated histone $\mathrm{H} 3$ and $\mathrm{H} 4$ from LA homogenates from naive $(n=8)$, nonreactivated $(n=7)$, and reactivated rats $(n=7)$ sacrificed 60 min after reactivation session. (D) Western blot analysis of total histone $\mathrm{H} 3$ and H4 from LA homogenates from naive $(n=8)$, nonreactivated $(n=7)$, and reactivated rats $(n=7)$ sacrificed $60 \mathrm{~min}$ after reactivation session. (E) Western blot analysis of acetylated histone $\mathrm{H} 3$ and $\mathrm{H} 4$ from LA homogenates from naive $(n=$ $8)$, nonreactivated $(n=6)$, and reactivated $(n=9)$ rats sacrificed 90 min after reactivation session. ${ }^{*} P<0.05$ relative to nonreactivated and naive groups. $(F)$ Western blot analysis of total histone $\mathrm{H} 3$ and $\mathrm{H} 4$ from LA homogenates from naive $(n=8)$, nonreactivated $(n=6)$, and reactivated $(n=$ 9) rats sacrificed $90 \mathrm{~min}$ after reactivation session. (G) Western blot analysis of acetylated histone $\mathrm{H} 3$ and $\mathrm{H} 4$ from LA homogenates from naive $(n=$ 8), nonreactivated $(n=7)$, and reactivated $(n=6)$ rats sacrificed 120 min after reactivation session. $(H)$ Western blot analysis of total histone H3 and H4 from LA homogenates from naive $(n=8)$, nonreactivated $(n=7)$, and reactivated $(n=6)$ rats sacrificed 120 min after reactivation session. For each time point, representative Western blots are depicted in the inset. 


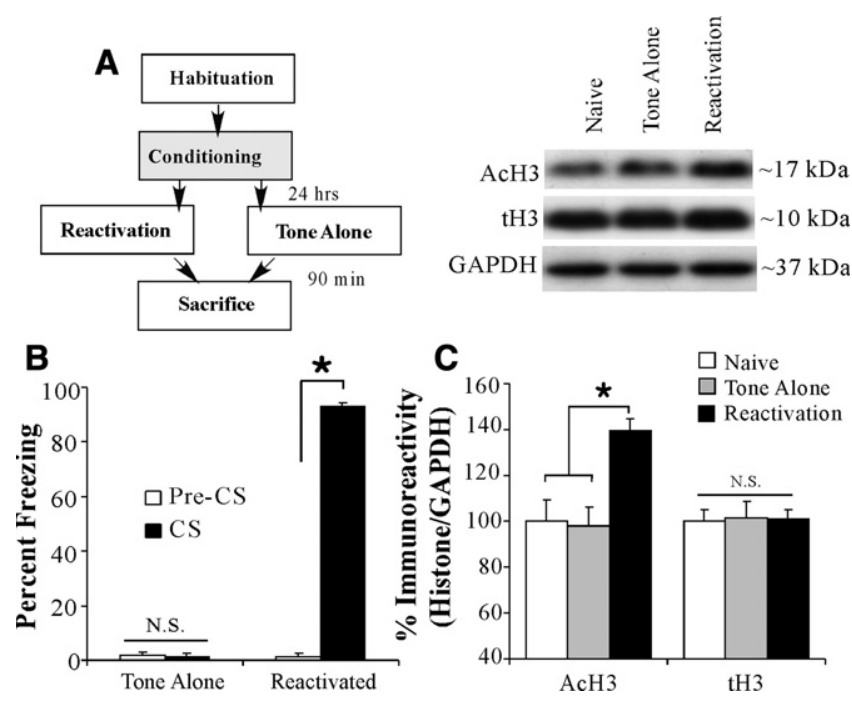

Figure 2. The regulation of histone $\mathrm{H} 3$ acetylation in the LA is specific to fear memory retrieval. $(A)$ Schematic of the behavioral protocol. During training, rats received either two tone-shock pairings (reactivated) or two presentations of the tone alone (tone alone). The next day, all rats received a memory reactivation trial followed by sacrifice 90 min later $(B)$ Memory reactivation scores for the tone alone and reactivated groups. (C) Western blot analysis of histone $\mathrm{H} 3$ acetylation in the LA of reactivated $(n=6)$, tone alone $(n=6)$, and naive $(n=6)$ groups after fear memory retrieval. Representative blots can be viewed in the inset. $* P<0.05$ relative to naive and tone alone groups.

histone H3 $\left(t_{(10)}=0.29\right)$, H4 $\left(t_{(10)}=0.33\right)($ Fig. 3C, right), or in the loading protein GAPDH $\left(t_{(10)}=0.15\right)$ (data not shown).

\section{Histone deacetylase inhibition in the LA enhances auditory fear memory reconsolidation}

To examine the effect of histone deacetylase inhibition on auditory fear memory reconsolidation, rats were trained with two tone-shock pairings in Chamber A, followed $24 \mathrm{~h}$ later by auditory fear memory reactivation administered in Chamber B. One hour following reactivation, rats received intra-LA infusion of either vehicle $(0.5 \mu \mathrm{L} /$ side $)$ or the HDAC inhibitor TSA $(1 \mu \mathrm{g}$ in 0.5 $\mu \mathrm{L} /$ side), followed $\sim 24 \mathrm{~h}$ later by a test of PR-LTM (Fig. 3D). There was no difference in levels of pre- vs. post-shock freezing between the vehicle and TSA groups (Fig. 3E). The ANOVA (group by trial) revealed a significant main effect of trial $\left(F_{(2,24)}=\right.$ 1221.64, $P<0.01)$, yet failed to reveal a significant main effect of group $\left(F_{(1,12)}=1.17\right)$ or group by trial interaction $\left(F_{(2,24)}=\right.$ 0.97). Further, on the next day, both groups showed equivalent levels of freezing during the preCS period and the tone-CS presentation during the reactivation trial (Fig. 3F). An ANOVA (group by trial) revealed no significant effect of group $\left(F_{(1,12)}=0.24\right)$ or group by trial interaction $\left(F_{(1,12)}=0.23\right)$; however, there was a significant main effect of trial $\left(F_{(1,12)}=895.6, P<0.01\right)$, indicating that there was an increase in freezing to the tone CS relative to the preCS period in both groups. The next day, the group infused with TSA exhibited enhanced PR-LTM (Fig. 3G). The ANOVA (group by trial) revealed significant main effects of group $\left(F_{(1,12)}=96.9, P<0.01\right)$ and trial $\left(F_{(9,108)}=3.74, P<0.01\right)$, but no significant group by trial interaction $\left(F_{(9,108)}=0.34\right)$. Cannula placements are shown in Figure 3L.

Next, we examined the effect of HDAC inhibition on PR-STM. Separate groups of rats were trained, reactivated, and infused with vehicle or TSA as before, followed $3 \mathrm{~h}$ later by a test of PR-STM (Fig. 3H). There was no difference in levels of pre- vs. post-shock freezing between the vehicle and TSA groups (Fig. 3I). The ANOVA (group by trial) revealed only a significant main effect of trial $\left(F_{(2,22)}=834.9, P<0.01\right)$; there was no significant main effect of group $\left(F_{(1,11)}=0.001\right)$ or the group by trial interaction $\left(F_{(2,22)}=0.66\right)$. Further, on the next day, both groups showed equivalent levels of freezing during the preCS period and the tone-CS presentation during the reactivation trial (Fig. 3J). An ANOVA (group by trial) revealed no significant effect of group $\left(F_{(1,11)}=0.08\right)$, or group by trial interaction $\left(F_{(1,11)}=\right.$ $0.69)$; however, there was a significant main effect of trial $\left(F_{(1,11)}=1581.6, P<0.01\right)$, indicating that there was an increase in freezing to the tone CS relative to the preCS period in both groups. Three hours following tone memory reactivation, rats were given a test of PR-STM (Fig. 3K). The ANOVA (group by trial) revealed no significant effect of group $\left(F_{(1,11)}=0.7\right)$, trial $\left(F_{(2,22)}=\right.$ $0.25)$, and no group by trial interaction $\left(F_{(2,22)}=0.08\right)$. Cannula placements are shown in Figure 3M.

\section{The effect of HDAC inhibition on reconsolidation of an auditory fear memory is specific to an actively reactivated memory}

To determine whether the reconsolidation enhancement produced by HDAC inhibition is specific to an actively retrieved memory, we next examined the effect of intra-LA HDAC inhibition on memory reconsolidation in the absence of fear memory reactivation (Fig. 4). Rats were trained in Chamber A with two tone-shock pairings (as above), followed $24 \mathrm{~h}$ later by a no-reactivation session administered in Chamber B. During the no-reactivation session, rats were placed in Chamber B for the same amount of time as those rats which received tone reactivation in the previous experiment but were not presented with a tone. One hour following the no-reactivation session, rats received intra-LA infusion of either vehicle $(0.5 \mu \mathrm{L} /$ side $)$ or the HDAC inhibitor TSA $(1 \mu \mathrm{g}$ in $0.5 \mu \mathrm{L} /$ side) followed $\sim 24 \mathrm{~h}$ later by a test of PR-LTM (Fig. 4A).

There was no difference in levels of pre- vs. post-shock freezing between the vehicle and TSA groups (Fig. 4B). The ANOVA (group by trial) revealed a significant main effect of trial $\left(F_{(2,16)}=369.7, P<0.01\right)$, yet failed to reveal a significant main effect of group $\left(F_{(1,8)}=0.23\right)$ or the group by trial interaction $\left(F_{(2,16)}=0.23\right)$. On the next day, both groups showed equivalent levels of freezing during the "preCS" period and during the 30 sec when the tone would have been presented during the reactivation trial (Fig. 4C). An ANOVA (group by trial) revealed no significant effect of group $\left(F_{(1,8)}=0.44\right)$, trial $\left(F_{(1,8)}=2.0\right)$, or group by trial interaction $\left(F_{(1,8)}=0.001\right)$. Examination of freezing during the PR-LTM test also revealed no significant difference between the groups (Fig. 4D). The ANOVA (group by trial) failed to reveal a significant main effect of group $\left(F_{(1,8)}=0.08\right)$, trial $\left(F_{(9,72)}=\right.$ $0.48)$, or group by trial interaction $\left(F_{(9,72)}=0.39\right)$. Cannula placements can be viewed in Figure 4I.

\section{The memory enhancing effect of HDAC inhibition in the LA on auditory fear memory reconsolidation is time-limited}

We have shown that HDAC inhibition in the LA enhances auditory fear memory reconsolidation. Next, we asked whether this effect is temporally constrained. Trained rats were given a tone reactivation trial, followed $6 \mathrm{~h}$ later by intra-LA infusion of either TSA $(1 \mu \mathrm{g} / 0.5 \mu \mathrm{L} /$ side $)$ or vehicle $(0.5 \mu \mathrm{L} /$ side $)$, followed by a PR-LTM test $18 \mathrm{~h}$ later (Fig. 4E). There was no significant difference between the TSA- and vehicle-infused groups in the level of post-shock freezing following training (Fig. 4F). The ANOVA (group by trial) revealed a main effect of trial $\left(F_{(2,22)}=1020.05\right.$, $P<0.01)$, but no significant main effect of group $\left(F_{(1,11)}=0.66\right)$ 

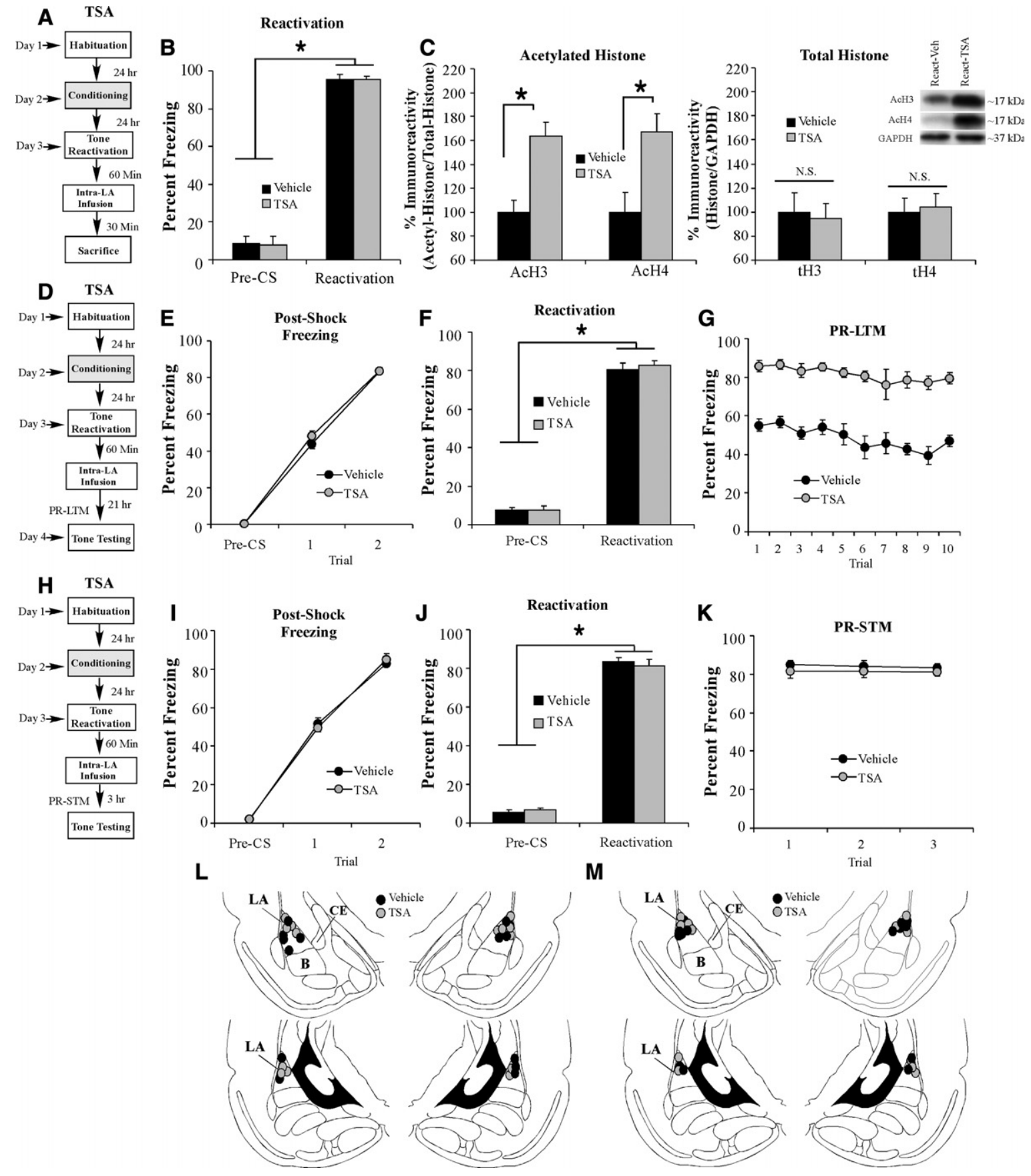

M

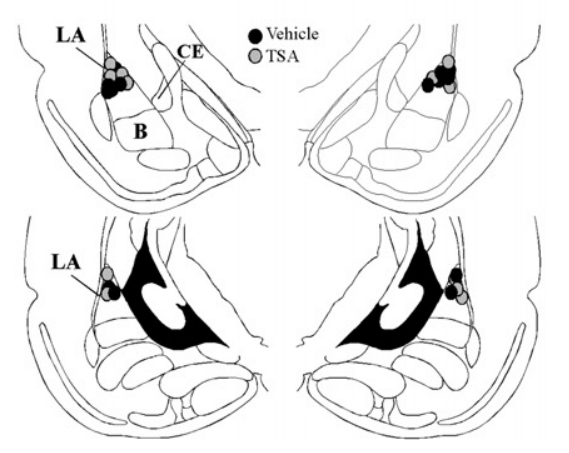

Figure 3. Intra-LA infusion of an HDAC inhibitor enhances retrieval-related $\mathrm{H} 3$ acetylation and auditory fear memory reconsolidation. (A) Schematic of the behavioral protocol. Rats were trained, followed $24 \mathrm{~h}$ later by auditory fear memory retrieval administered in a distinct context. Sixty min after retrieval, rats were given intra-LA infusion of either vehicle or TSA $(1 \mu \mathrm{g}$ in $0.5 \mu \mathrm{L} /$ side) and were sacrificed 30 min later. (B) Memory retrieval data for vehicle $(n=6)$ and TSA-infused groups $(n=6)$. ${ }^{*} P<0.05$ relative to the preCS period. (C) (Left) Western blot analysis of acetylated histone H3 and H4 from LA homogenates from vehicle and TSA-infused rats, and (right) Western blot analysis of total histone H3 and H4 from LA homogenates from vehicle and TSA-infused rats. Representative blots can be viewed in the inset. (D) Schematic of the behavioral protocol. Rats were trained, followed $24 \mathrm{~h}$ later by auditory fear memory retrieval administered in a distinct context, and given intra-LA infusion of either TSA $(1 \mu \mathrm{g}$ in $0.5 \mu \mathrm{L} / \mathrm{side})(n=7)$ or vehicle $(0.5 \mu \mathrm{L} /$ side) $(n=7) 60$ min later. Post-reactivation long-term memory (PR-LTM) was examined $24 \mathrm{~h}$ following the reactivation trial. (E) Post-shock freezing scores in each group immediately after the conditioning trials. $(F)$ Memory reactivation scores in each group during the tone reactivation trial. $(G)$ Auditory fear memory assessed $24 \mathrm{~h}$ after reactivation in each group across all 10 tone presentations. $(H)$ Schematic of the behavioral protocol. Rats were trained, followed $24 \mathrm{~h}$ later by auditory fear memory retrieval administered in a distinct context, and given intra-LA infusion of either TSA $(1 \mu \mathrm{g}$ in $0.5 \mu \mathrm{L} /$ side) $(n=6)$ or vehicle $(0.5 \mu \mathrm{L} / \mathrm{side})(n=7) 60 \mathrm{~min}$ later. Post-reactivation short-term memory (PR-STM) was examined $3 \mathrm{~h}$ following the reactivation trial. (I) Post-shock freezing scores in each group immediately after the conditioning trials. (/) Memory reactivation scores in each group during the tone reactivation trial. ( $K$ ) Auditory fear memory assessed at $3 \mathrm{~h}$ after memory reactivation in each group across all three tone presentations. (L) Histological verification of cannula placements for rats infused with TSA (gray circles) or vehicle (black circles) and tested for PR-LTM. (M) Histological verification of cannula placements for rats infused with TSA (gray circles) or vehicle (black circles) and tested for PR-STM. (Panels were adapted from Paxinos and Watson [1998] with permission from Elsevier $\mathbb{C}$ 1998.) 

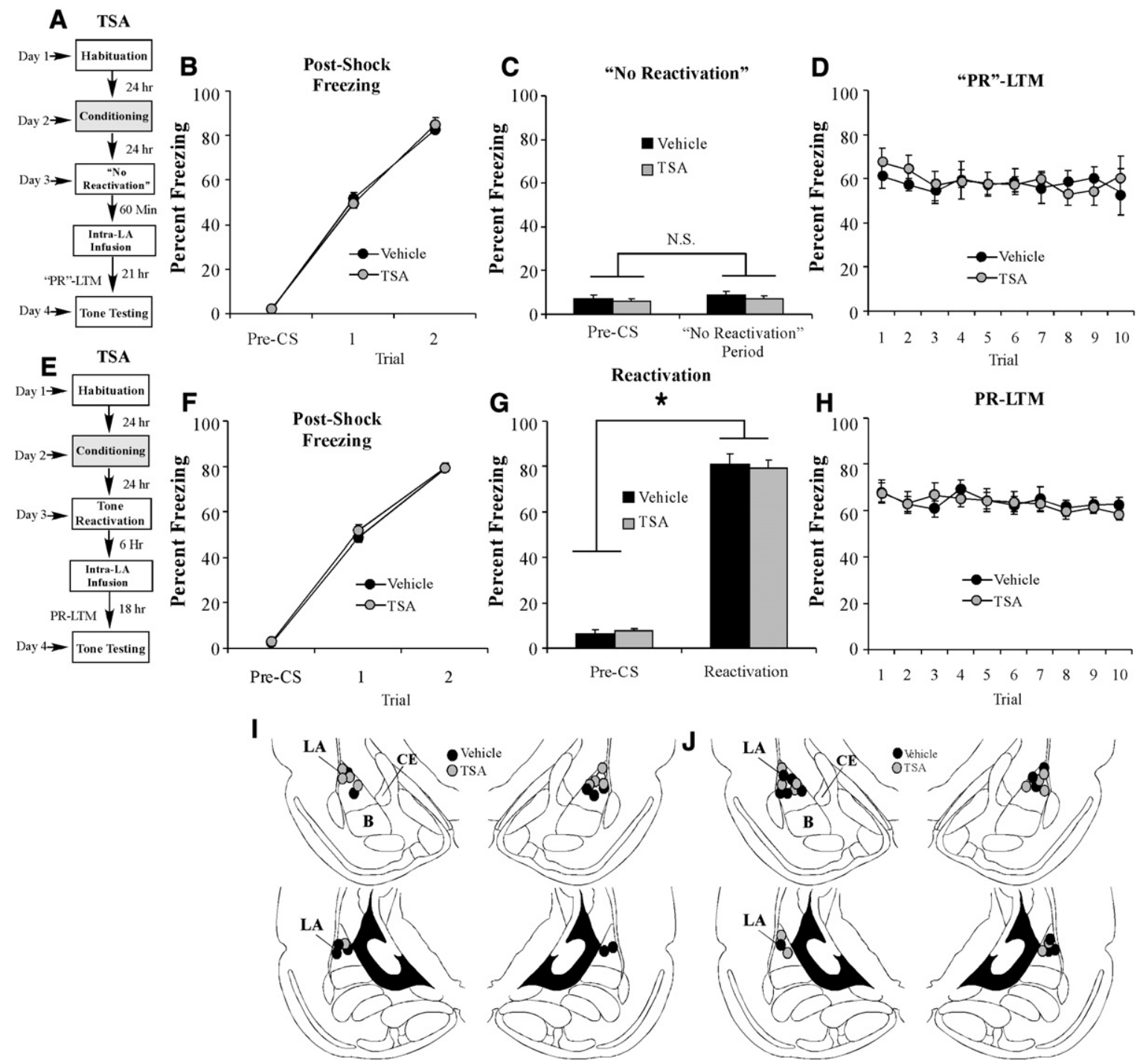

Figure 4. The effect of HDAC inhibition on auditory fear memory reconsolidation is specific to reactivated memories and time-limited. ( $A$ ) Schematic of the behavioral protocol. Rats were trained, followed $24 \mathrm{~h}$ later by a no-reactivation trial in which rats were placed in a distinct context without tone-CS presentation. Sixty min later, rats given intra-LA infusion of either TSA ( $1 \mu \mathrm{g}$ in $0.5 \mu \mathrm{L} / \mathrm{side})(n=5)$ or vehicle $(0.5 \mu \mathrm{L} / \mathrm{side})(n=5)$. "PR"-LTM was examined $24 \mathrm{~h}$ following the no-reactivation trial. (B) Post-shock freezing scores in each group immediately after the conditioning trials. (C) Memory reactivation scores in each group during the no-reactivation trial. $(D)$ Auditory fear memory assessed $24 \mathrm{~h}$ after no-reactivation in each group across all 10 tone presentations. (E) Schematic of the behavioral paradigm. Rats were trained, followed $24 \mathrm{~h}$ later by a tone reactivation session in a distinct context. Rats were then given intra-LA infusion of either TSA $(1 \mu \mathrm{g}$ in $0.5 \mu \mathrm{L} / \mathrm{side})(n=7)$ or vehicle $(0.5 \mu \mathrm{L} / \mathrm{side})(n=6) 6 \mathrm{~h}$ later. Auditory fear memory was assessed $24 \mathrm{~h}$ after reactivation (18 h after infusion). $(F)$ Post-shock freezing scores in each group immediately after the conditioning trials. ( $G$ ) Memory reactivation scores in each group during the tone reactivation trial. $(H)$ Auditory fear memory assessed $18 \mathrm{~h}$ after infusions for both groups across all 10 tone presentations. (I) Histological verification of cannula placements for rats infused with TSA (gray circles) or vehicle (black circles) in the no-reactivation experiment. (/) Histological verification of cannula placements for rats infused with TSA (gray circles) or vehicle (black circles) in the delayed infusion experiment. (Panels were adapted from Paxinos and Watson [1998] with permission from Elsevier (1) 1998.)

or the group by trial interaction $\left(F_{(2,22)}=0.32\right)$. On the next day, both groups exhibited equivalent levels of tone memory reactivation (Fig. 4G). An ANOVA (group by trial) revealed no significant main effect of group $\left(F_{(1,11)}=0.10\right)$ or group by trial interaction $\left(F_{(1,11)}=0.54\right)$; however, there was a significant main effect of trial $\left(F_{(1,11)}=911.8, P<0.01\right)$, indicating that there was an increase in freezing to the tone CS relative to the preCS period. Furthermore, no significant group difference in freezing levels was observed during the PR-LTM test (Fig. 4H). The ANOVA revealed nonsignificant effects for group $\left(F_{(1,11)}=0.03\right)$, trial $\left(F_{(9,99)}=1.62\right)$, and the group by trial interaction $\left(F_{(9,99)}=0.56\right)$. Cannula placements can be viewed in Figure 4J. Thus, these findings are consistent with the time-limited window of memory lability (Nader et al. 2000) which likely occur within $6 \mathrm{~h}$ of memory retrieval.

\section{Inhibition of DNA methyltransferase activity in the LA impairs auditory fear memory reconsolidation}

DNA methylation has been shown to negatively regulate memory via its ability to repress gene transcription (Levenson and Sweatt 2006; Miller and Sweatt 2007). Interestingly, several recent studies have shown that inhibition of DNMT activity results in deficits in memory consolidation in both hippocampal- (Levenson et al. 2004; Miller et al. 2008; Zhao et al. 2010) and amygdala-dependent 
(Monsey et al. 2011) memory tasks. The role of DNMT activity in memory reconsolidation processes, however, has never been studied.

\section{Inhibition of DNA methyltransferase activity in the LA impairs fear memory reconsolidation}

To examine the role of DNA methylation in auditory fear memory reconsolidation, rats were trained in Chamber A with three toneshock pairings, followed $24 \mathrm{~h}$ later by auditory fear memory reactivation administered in Chamber B. One hour after reactivation, rats received intra-LA infusion of vehicle $(0.5 \mu \mathrm{L} /$ side $)$ or one of two different DNMT inhibitors: the nucleoside analogue 5-AZA ( $1 \mu \mathrm{g}$ in $0.5 \mu \mathrm{L} /$ side) or the nonnucleoside DNMT inhibitor RG108 (1 $\mu$ g in $0.5 \mu \mathrm{L} /$ side). All rats were tested for PR-LTM $\sim 24$ h later (Fig. 5A). There was no difference in levels of pre- vs. post-shock freezing between the vehicle, 5-AZA, or RG108 groups (Fig. 5B). The ANOVA (group by trial) revealed a significant main effect of trial $\left(F_{(3,57)}=489.56, P<0.01\right)$ but failed to reveal a significant main effect of group $\left(F_{(2,19)}=0.24\right)$ or group by trial interaction $\left(F_{(6,57)}=0.45\right)$. Further, on the next day, both groups showed equivalent levels of freezing during the preCS period

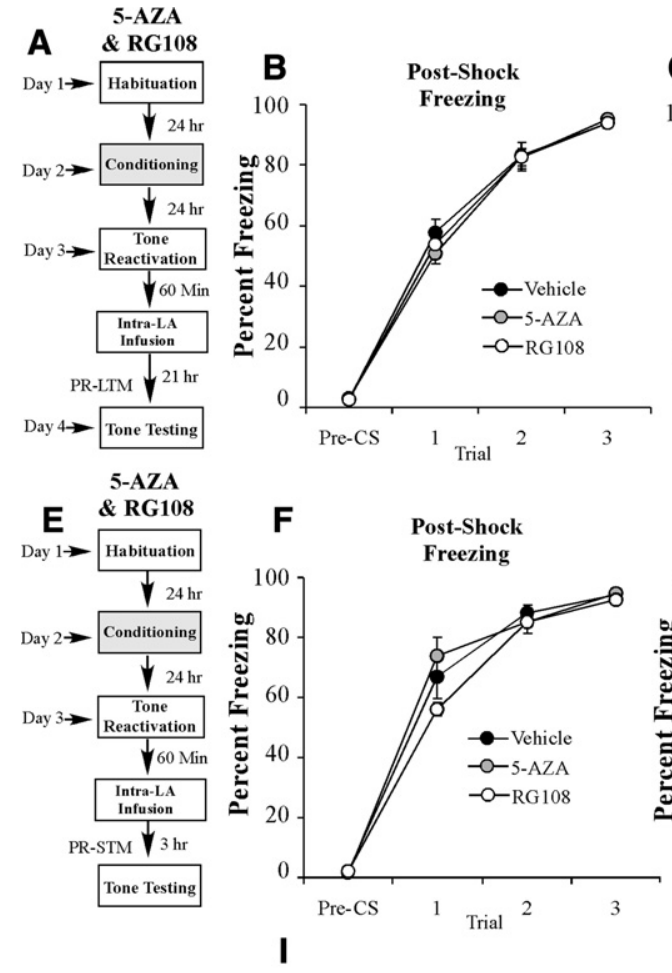

I
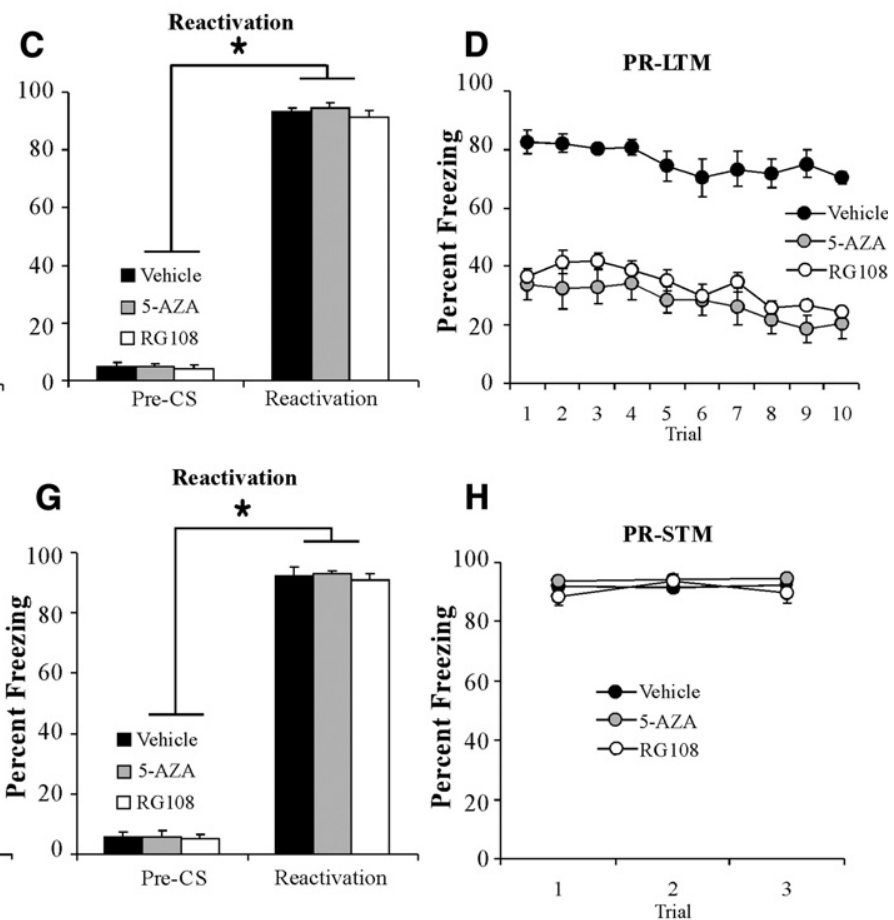

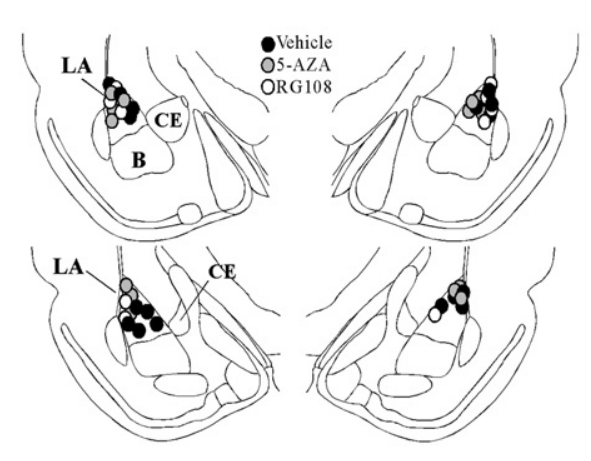

$\mathbf{J}$

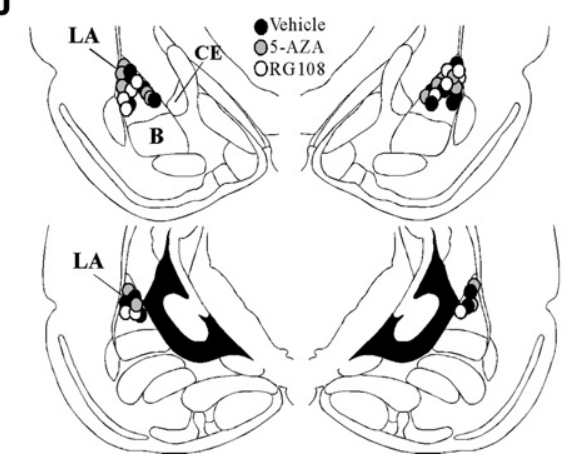

Figure 5. Intra-LA infusion of a DNMT inhibitor interferes with auditory fear memory reconsolidation. ( $A$ ) Schematic of the behavioral protocol. Rats were trained, followed $24 \mathrm{~h}$ later by auditory fear memory retrieval administered in a distinct context, and given intra-LA infusion of either 5 -AZA (1 $\mu \mathrm{g}$ in $0.5 \mu \mathrm{L} /$ side) $(n=7)$, RG108 ( $1 \mu \mathrm{g}$ in $0.5 \mu \mathrm{L} /$ side) $(n=5)$, or vehicle $(0.5 \mu \mathrm{L} / \mathrm{side})(n=9) 60$ min later. PR-LTM was examined $24 \mathrm{~h}$ following the reactivation trial. (B) Post-shock freezing scores in each group immediately after the conditioning trials. (C) Memory reactivation scores in each group during the tone reactivation trial. $(D)$ Auditory fear memory assessed $24 \mathrm{~h}$ after reactivation in each group across all 10 tone presentations. ( $E$ ) Schematic of the behavioral protocol. Rats were trained, followed $24 \mathrm{~h}$ later by auditory fear memory retrieval administered in a distinct context, and given intra-LA infusion of either 5 -AZA $(1 \mu \mathrm{g}$ in $0.5 \mu \mathrm{L} /$ side $)(n=7)$, RG108 $(1 \mu \mathrm{g}$ in $0.5 \mu \mathrm{L} /$ side $)(n=6)$, or vehicle $(0.5 \mu \mathrm{L} / \mathrm{side})(n=8) 60 \mathrm{~min}$ later. PR-STM was examined $3 \mathrm{~h}$ following the reactivation trial. $(F)$ Post-shock freezing scores in each group immediately after the conditioning trials. ( $G$ ) Memory reactivation scores in each group during the tone reactivation trial. $(H)$ Auditory fear memory assessed at $3 \mathrm{~h}$ after memory reactivation in each group across all three tone presentations. (I) Histological verification of cannula placements for rats infused with 5-AZA (gray circles), RG108 (white circles), or vehicle (black circles) and tested for PR-LTM. ( $)$ Histological verification of cannula placements for rats infused with 5-AZA (gray circles), RG108 (white circles), or vehicle (black circles) and tested for PR-STM. (Panels were adapted from Paxinos and Watson [1998] with permission from Elsevier (C) 1998.) 
and the tone-CS presentation during the reactivation trial (Fig. 5C). An ANOVA (group by trial) revealed no significant effect of group $\left(F_{(2,19)}=0.31\right)$ or group by trial interaction $\left(F_{(2,19)}=\right.$ $0.31)$; however, there was a significant main effect of trial $\left(F_{(1,19)}=1140.1, P<0.01\right)$, indicating that there was an increase in freezing to the tone $\mathrm{CS}$ relative to the preCS period in all groups. The next day, the groups infused with 5-AZA or RG108 exhibited impaired PR-LTM (Fig. 5D). The ANOVA (group by trial) revealed significant main effects of group $\left(F_{(2,18)}=68.89, P<0.01\right)$ and trial $\left(F_{(9,162)}=6.90, P<0.01\right)$, but no significant group by trial interaction $\left(F_{(18,162)}=0.51\right)$. A Duncan's post-hoc test for the main effect of group revealed that the vehicle group was significantly different from both the 5-AZA and RG108 groups $(P<$ $0.01)$, which were not found to be significantly different from one another $(P>0.05)$. Cannula placements are shown in Figure 5I.

Next, we examined the effect of DNMT inhibition on PR-STM. Separate groups of rats were trained, reactivated, and infused with vehicle, 5-AZA, or RG108 as before, followed $3 \mathrm{~h}$ later by a test of PR-STM (Fig. 5E). There was no difference in levels of pre- vs. post-shock freezing between the vehicle, 5-AZA, or RG108 groups (Fig. 5F). The ANOVA (group by trial) revealed only a significant main effect of trial $\left(F_{(3,57)}=428.87, P<0.01\right)$; there was no significant main effect of group $\left(F_{(2,19)}=1.22\right)$ or the group by trial interaction $\left(F_{(6,57)}=0.99\right)$. Further, on the next day, all groups showed equivalent levels of freezing during the preCS period and the tone-CS presentation during the reactivation trial (Fig. 5G). An ANOVA (group by trial) revealed no significant effect of group $\left(F_{(2,19)}=0.23\right)$ or group by trial interaction $\left(F_{(2,19)}=0.45\right)$; however, there was a significant main effect of trial $\left(F_{(1,19)}=1192.38, P<0.01\right)$, indicating that there was an increase in freezing to the tone CS relative to the preCS period in all groups. Three hours following tone memory reactivation, rats were given a PR-STM test (Fig. 5H). The ANOVA (group by trial) revealed no significant effect of group $\left(F_{(2,19)}=0.15\right)$ or trial $\left(F_{(2,38)}=2.31\right.$, $P>0.05)$, and no group by trial interaction $\left(F_{(4,38)}=1.04\right)$. Cannula placements are shown in Figure 5J.

\section{The effect of DNMT inhibition on reconsolidation of an auditory fear memory is specific to an actively reactivated memory}

To determine whether the reconsolidation deficit produced by DNMT inhibition in the LA is specific to an actively reactivated memory, we next examined the effect of DNMT inhibition on memory reconsolidation in the absence of fear memory reactivation. Rats were trained in Chamber A with three tone-shock pairings, followed $24 \mathrm{~h}$ later by a no-reactivation session administered in Chamber B, and infused with vehicle, 5-AZA, or RG108 as above (Fig. 6A). There was no difference in levels of pre- vs. postshock freezing between the vehicle, 5-AZA, or RG108 groups (Fig. 6B). The ANOVA (group by trial) revealed a significant main effect of trial $\left(F_{(3,48)}=544.92, P<0.01\right)$, yet failed to reveal a significant main effect of group $\left(F_{(2,16)}=1.64\right)$ or the group by trial interaction $\left(F_{(6,48)}=0.80\right)$. On the next day, all three groups showed equivalent levels of freezing during the "preCS" period and during the $30 \mathrm{sec}$ when the tone would have been presented during the reactivation trial (Fig. 6C). An ANOVA (group by trial) revealed no significant effect of group $\left(F_{(2,16)}=0.56\right)$, trial $\left(F_{(1,16)}=2.74\right)$, or group by trial interaction $\left(F_{(2,16)}=0.12\right)$. Examination of freezing during the PR-LTM test also revealed no significant difference between the groups, with all three groups displaying high levels of freezing (Fig. 6D). The ANOVA (group by trial) failed to reveal a significant main effect of group $\left(F_{(2,16)}=0.46\right)$ or group by trial interaction $\left(F_{(18,144)}=1.22\right)$; however, there was a significant main effect of trial $\left(F_{(9,144)}=4.04, P<\right.$ 0.05). Cannula placements can be viewed in Figure 6I.

\section{The effect of DNMT inhibition in the LA on auditory fear memory reconsolidation is time-limited}

Next, we asked whether the effect of intra-LA DNMT inhibition on memory reconsolidation has temporal constraints. Trained rats were given a tone reactivation trial, followed $6 \mathrm{~h}$ later by intra-LA infusion of either 5-AZA or vehicle $(1 \mu \mathrm{g}$ in $0.5 \mu \mathrm{L} /$ side), followed by a PR-LTM test $18 \mathrm{~h}$ later (Fig. 6E). There was no significant difference between the 5-AZA- and vehicle-infused groups in the level of post-shock freezing following training (Fig. 6F). The ANOVA revealed a main effect of trial $\left(F_{(3,33)}=\right.$ 309.09, $P<0.01)$, but no significant main effect of group $\left(F_{(1,11)}=0.36\right)$ or the group by trial interaction $\left(F_{(3,33)}=1.17\right)$. On the next day, both groups exhibited equivalent levels of tone memory reactivation (Fig. 6G). An ANOVA (group by trial) revealed no significant effect of group $\left(F_{(1,11)}=0.12\right)$ or group by trial interaction $\left(F_{(1,11)}=0.001\right)$; however, there was a significant main effect of trial $\left(F_{(1,11)}=3785.2, P<0.01\right)$, indicating that there was an increase in freezing to the tone CS relative to the preCS period. Furthermore, no significant group difference in freezing levels was observed during the PR-LTM test (Fig. 6H). The ANOVA revealed a nonsignificant effect for group $\left(F_{(1,11)}=\right.$ $0.39)$ and group by trial interaction $\left(F_{(9,99)}=0.85\right)$; however, there was a significant effect of trial $\left(F_{(9,99)}=9.04, P<0.05\right)$. Cannula placements can be viewed in Figure 6J.

\section{The reconsolidation deficit induced by DNMT inhibition is not sensitive to spontaneous recovery, reinstatement, or to a shift in testing context}

Our experiments thus far collectively suggest that DNMT inhibition in the LA impairs reconsolidation of an auditory fear memory. An alternative interpretation, however, is that DNMT inhibition has facilitated fear memory extinction. To distinguish among these possibilities, we examined whether the reconsolidation deficit induced by DNMT inhibition in the LA is sensitive to spontaneous recovery, reinstatement, or to a shift in the testing context, all features that are characteristic of extinguished fear memories (Pavlov 1927; Bouton and Bolles 1979a,b). Rats were trained with three tone-shock pairings in Chamber A, followed $24 \mathrm{~h}$ later by a reactivation trial in Chamber B. One hour later, rats were given intra-LA infusion of either 5-AZA ( $1 \mu \mathrm{g}$ in 0.5 $\mu \mathrm{L} /$ side) or vehicle $(0.5 \mu \mathrm{L} /$ side $)$. Twenty-four hours later, all rats were tested for PR-LTM in Context B (Fig. 7A). One week later, rats were retested for PR-LTM in Chamber B to test for spontaneous recovery of the fear memory. The next day, rats underwent a fear reinstatement session in a novel context (Chamber C), consisting of exposure to three unsignaled footshocks (Duvarci and Nader 2004), followed $24 \mathrm{~h}$ later by a third test of PR-LTM in Chamber B (Reinstatement Test). Finally, rats were placed in a third novel context (Chamber D) and retested for PR-LTM to examine the generality of the memory reconsolidation deficit (Context Shift) (Fig. 7A).

There was no difference in levels of post-shock freezing between the 5-AZA- and vehicle-infused groups (Fig. 7B). The ANOVA revealed only a significant main effect of trial $\left(F_{(3,30)}=\right.$ 237.39, $P<0.01$ ); there was no significant main effect of group $\left(F_{(1,10)}=0.16\right)$ or group by trial interaction $\left(F_{(3,30)}=0.76\right)$. Further, both groups showed equivalent levels of freezing during the preCS period and the tone-CS presentation during the reactivation trial (Fig. 7C). An ANOVA (group by trial) revealed no significant effect of group $\left(F_{(1,10)}=0.69\right)$ or group by trial interaction $\left(F_{(1,10)}=0.29\right)$; however, there was a significant main effect of trial $\left(F_{(1,10)}=3322.58, P<0.01\right)$, indicating that there was an increase in freezing to the tone CS relative to the preCS period in both groups. 

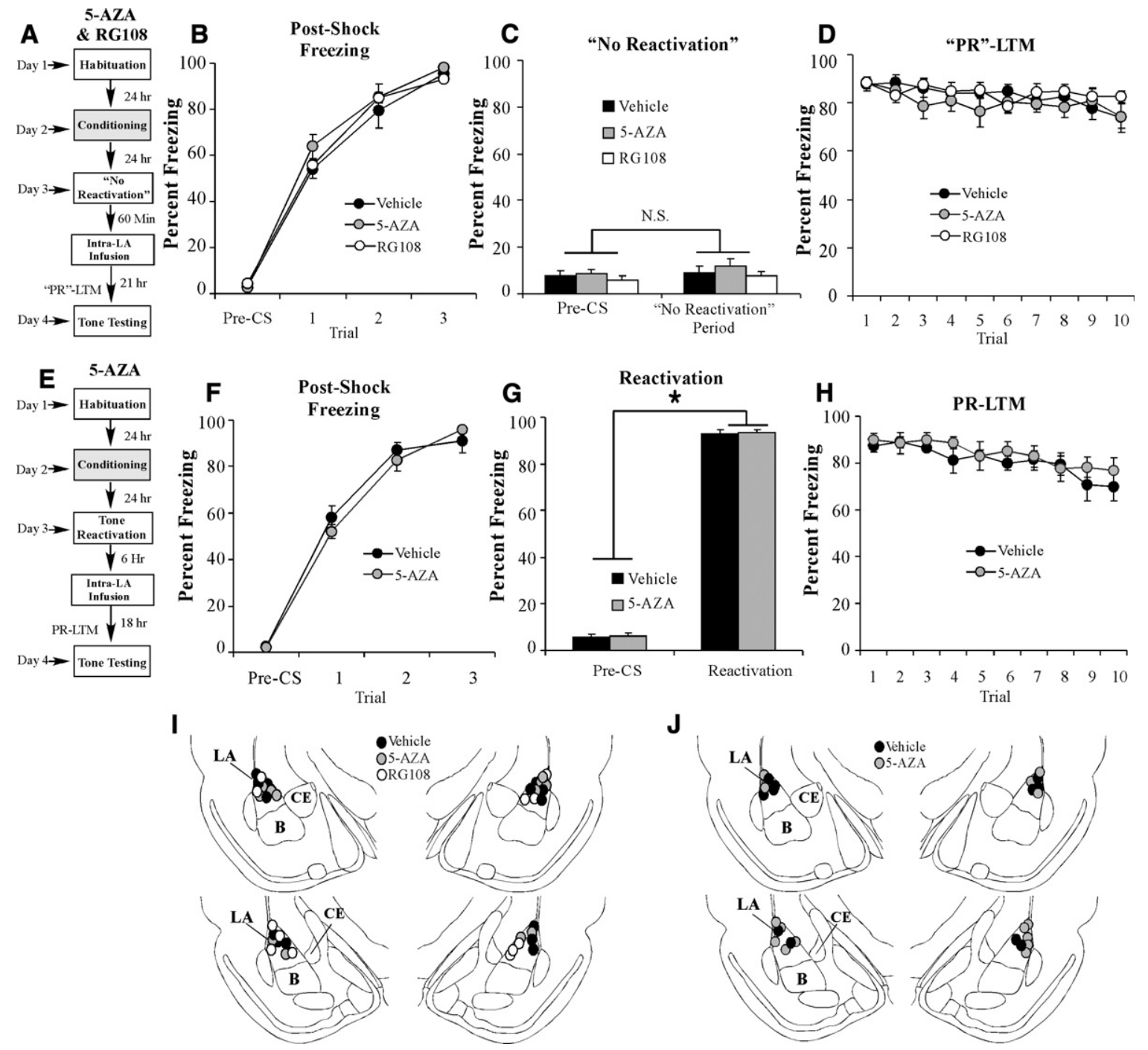

Figure 6. The effect of DNMT inhibition on auditory fear memory reconsolidation is specific to reactivated memories and time-limited. $(A)$ Schematic of the behavioral protocol used to examine "PR"-LTM. Rats were trained, followed $24 \mathrm{~h}$ later by a no-reactivation trial in which rats were placed in a distinct context without tone-CS presentation. $60 \mathrm{~min}$ later, rats given intra-LA infusion of either 5-AZA ( $1 \mu \mathrm{g}$ in $0.5 \mu \mathrm{L} / \mathrm{side})(n=6)$, RG108 (1 $\mu \mathrm{g}$ in $0.5 \mu \mathrm{L} / \mathrm{side})$ $(n=6)$, or vehicle $(0.5 \mu \mathrm{L} /$ side) $(n=8)$. "PR" -LTM was examined $24 \mathrm{~h}$ following the no-reactivation trial. (B) Post-shock freezing scores in each group immediately after the conditioning trials. $(C)$ Memory reactivation scores in each group during the no-reactivation trial. $(D)$ Auditory fear memory assessed $24 \mathrm{~h}$ after no-reactivation in each group across all 10 tone presentations. (E) Schematic of the behavioral paradigm. Rats were trained, followed $24 \mathrm{~h}$ later by a tone reactivation session in a distinct context. Rats were then given intra-LA infusion of either 5-AZA $(1 \mu \mathrm{g}$ in $0.5 \mu \mathrm{L} /$ side $)(n=7)$ or vehicle $(0.5 \mu \mathrm{L} / \mathrm{side})(n=6) 6 \mathrm{~h}$ later. Auditory fear memory was assessed $24 \mathrm{~h}$ after reactivation ( $18 \mathrm{~h}$ after infusion). ( $F)$ Post-shock freezing scores in each group immediately after the conditioning trials. $(G)$ Memory reactivation scores in each group during the tone reactivation trial. $(H)$ Auditory fear memory assessed $18 \mathrm{~h}$ after infusions for both groups across all 10 tone presentations. (I) Histological verification of cannula placements for rats infused with 5-AZA (gray circles), RG108 (white circles), or vehicle (black circles) in the no-reactivation experiment. (J) Histological verification of cannula placements for rats infused with 5-AZA (gray circles) or vehicle (black circles) in the delayed infusion experiment. (Panels were adapted from Paxinos and Watson [1998] with permission from Elsevier (1) 1998.)

Examination of the PR-LTM test demonstrated that 5-AZAinfused rats exhibited impaired PR-LTM compared to vehicle controls (Fig. 7D). The ANOVA (group by trial) revealed significant main effects of group $\left(F_{(1,10)}=130.81, P<0.01\right)$ and trial $\left(F_{(9,90)}=6.96, P<0.05\right)$, but no significant group by trial interaction $\left(F_{(9,90)}=1.23\right)$. During the test of spontaneous recovery one week later, 5-AZA-infused rats exhibited sustained memory impairment, while the vehicle control group retained high levels of fear memory (Fig. 7E). An ANOVA (group by trial) revealed significant main effects of group $\left(F_{(1,10)}=607.79, P<0.01\right)$ and trial $\left(F_{(4,40)}=10.90, P<0.01\right)$, and a significant group by trial interaction $\left(F_{(4,40)}=5.90, P<0.01\right)$.
During the reinstatement session, both vehicle and 5-AZA groups exhibited significant post-shock freezing in Chamber $\mathrm{C}$ (data not shown). An ANOVA (group by trial) revealed no main effect of group $\left(F_{(1,10)}=0.39\right)$ or group by trial interaction $\left(F_{(3,30)}=0.56\right)$, yet did reveal a significant main effect of trial $\left(F_{(3.30)}=409.81\right)$, suggesting an increase in freezing relative to the preshock period in both groups. When tested for reinstatement in Chamber B $24 \mathrm{~h}$ later, however, 5-AZA-infused rats continued to exhibit sustained memory impairment, while the vehicle control group exhibited high levels of freezing (Fig. 7F). An ANOVA (group by trial) revealed significant main effects of group $\left(F_{(1,10)}=584.04, P<0.01\right)$ and trial $\left(F_{(4,40)}=10.09, P<0.01\right)$, 


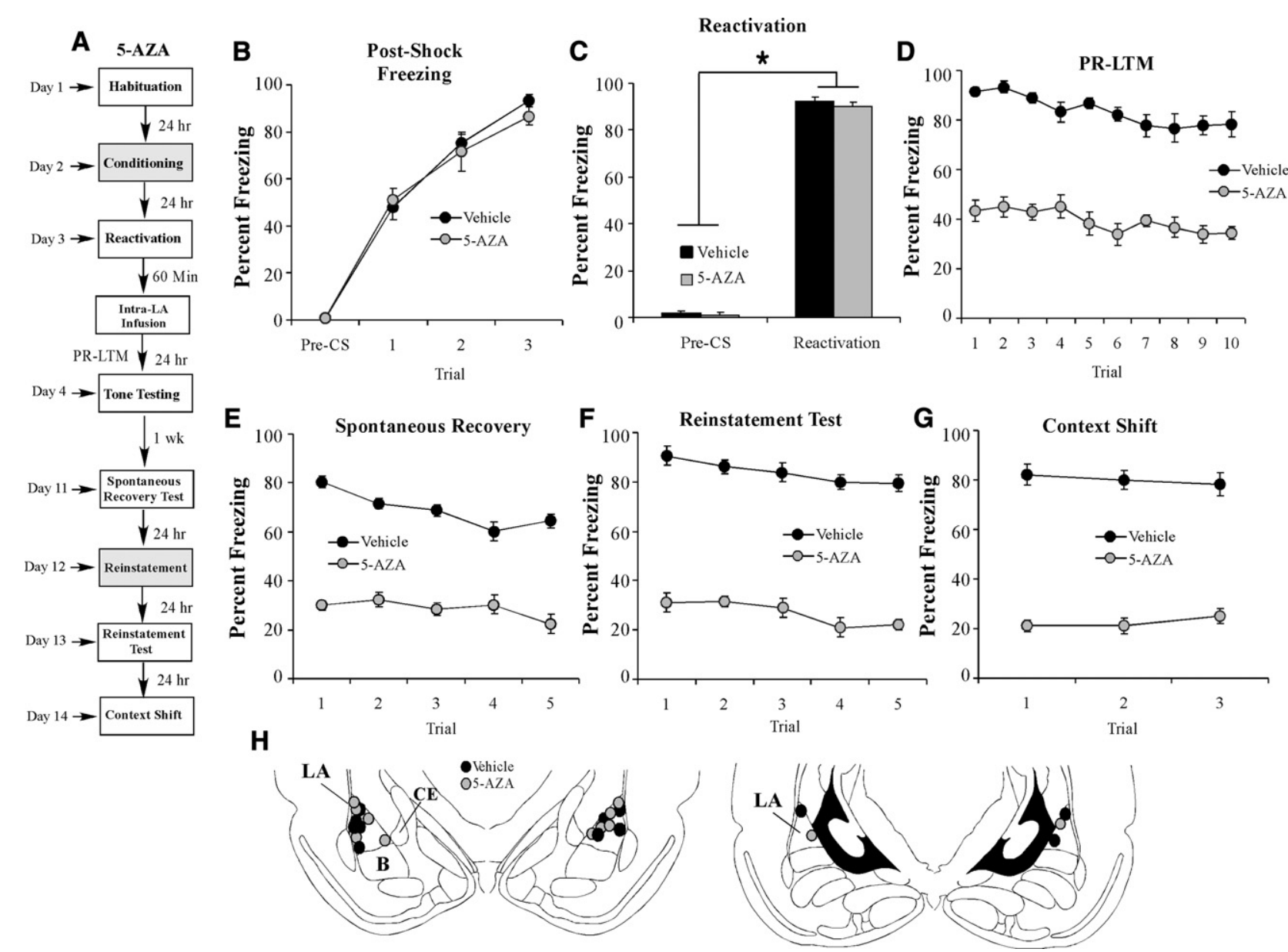

Figure 7. The effect of DNMT inhibition on auditory fear memory reconsolidation is not sensitive to spontaneous recovery, reinstatement, or to a shift in testing context. (A) Schematic of the behavioral protocol (see text for details). (B) Post-shock freezing scores in 5-AZA $(1 \mu \mathrm{g}$ in $0.5 \mu \mathrm{L} /$ side) $(n=6)$ and vehicle $(0.5 \mu \mathrm{L} /$ side $)(n=6)$ groups immediately after the conditioning trials. (C) Freezing scores in each group during the memory reactivation trial. (D) PR-LTM assessed $24 \mathrm{~h}$ after the reactivation trial in each group. (E) Spontaneous recovery assessed $1 \mathrm{wk}$ after the PR-LTM test. $(F)$ Reinstatement test assessed $24 \mathrm{~h}$ after the reinstatement session in each group. $(G)$ Context shift test assessed $24 \mathrm{~h}$ after the reinstatement test in each group. $(H)$ Histological verification of cannula placements for rats infused with 5-AZA (gray circles) or vehicle (black circles). (Panels were adapted from Paxinos and Watson [1998] with permission from Elsevier (1) 1998.)

but no significant group by trial interaction $\left(F_{(4,40)}=0.58\right)$, suggesting that the DNMT inhibition-induced reconsolidation deficit is not sensitive to reinstatement.

During the context shift test in Chamber D, 5-AZA-infused rats continued to exhibit sustained memory impairment, while the group infused with vehicle exhibited high levels of freezing, suggesting that the observed reconsolidation deficit is not context-specific (Fig. 7G). An ANOVA (group by trial) revealed a significant main effect of group $\left(F_{(1,10)}=150.32, P<0.01\right)$, but no effect of trial $\left(F_{(2,20)}=0.290\right)$ or the group by trial interaction $\left(F_{(2,20)}=2.79\right)$. Cannula placements are shown in Figure $7 \mathrm{H}$.

Histone acetylation and DNA methylation work in concert to regulate memory reconsolidation in the LA

Recent studies have suggested that one way in which DNMT inhibitors may negatively regulate memory formation is by influencing histone acetylation (Miller et al. 2008). For example, intra-CA1 infusion of a DNMT inhibitor has been shown to impair both contextual fear memory and the training-related increase in histone H3 acetylation in the hippocampus (Miller et al. 2008). Similarly, intra-LA infusion of a DNMT inhibitor has been shown to impair both auditory fear memory and the training-related increase in histone $\mathrm{H} 3$ acetylation in the LA (Monsey et al. 2011). Further, pretreatment with an HDAC inhibitor has been shown to rescue the memory deficit induced by a DNMT inhibitor (Miller et al. 2008; Monsey et al. 2011). In this series of experiments, we first examined whether intra-LA infusion of the DNMT inhibitor 5-AZA impairs training-related increases in histone $\mathrm{H} 3$ acetylation following memory retrieval. Next, we asked whether histone acetylation and DNA methylation work in concert during auditory fear memory reconsolidation by examining whether pretreatment with TSA can rescue the 5-AZA-induced reconsolidation deficit in the LA.

\section{DNMT inhibition impairs retrieval-related histone acetylation in the $L A$}

To examine the effect of intra-LA DNMT inhibition on retrievalinduced histone acetylation, rats were trained with three toneshock pairings as described above. Twenty-four hours later, rats received a memory reactivation trial, followed $1 \mathrm{~h}$ later by intra-LA infusion of vehicle $(0.5 \mu \mathrm{L} /$ side $)$ or 5 -AZA $(1 \mu \mathrm{g} / \mathrm{side})$. Rats were then sacrificed $30 \mathrm{~min}$ following infusion $(90 \mathrm{~min}$ following memory reactivation), and punches from the LA were taken and processed for Western blotting (Fig. 8A). Analysis of the behavioral data (preCS vs. CS freezing) for the vehicle and 

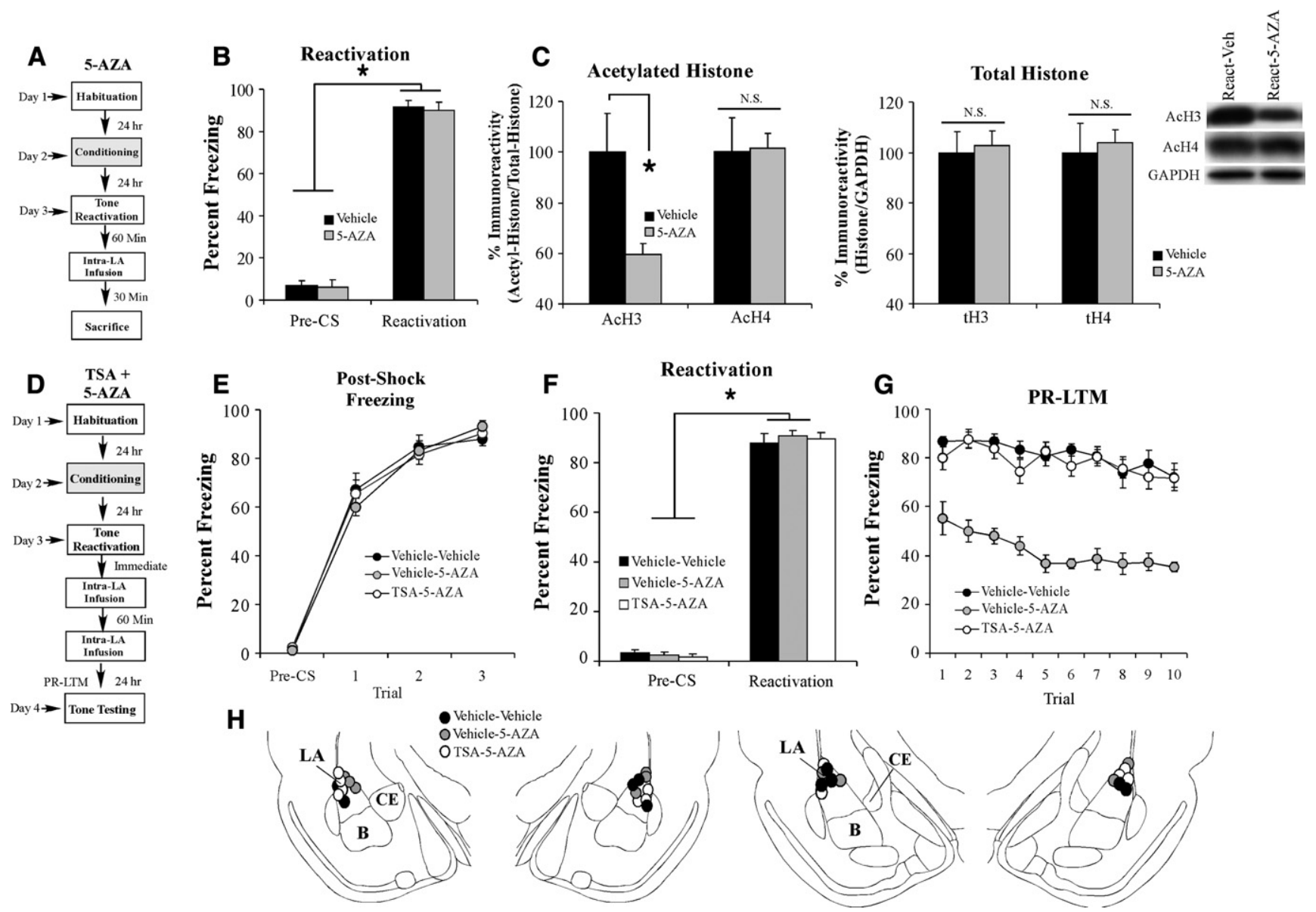

Figure 8. Histone acetylation and DNA methylation interact to regulate memory reconsolidation in the LA. (A) Schematic of the behavioral protocol. Rats were trained, followed $24 \mathrm{~h}$ later by auditory fear memory retrieval administered in a distinct context. Sixty min after retrieval, rats were given intra-LA infusion of either vehicle or 5-AZA ( $1 \mu \mathrm{g}$ in $0.5 \mu \mathrm{L} /$ side) and were sacrificed $30 \mathrm{~min}$ later. (B) Memory retrieval data for vehicle- $(n=8)$ and 5-AZA-infused groups $(n=7) .{ }^{*} P<0.05$ relative to the preCS period. (C) (Left) Western blot analysis of acetylated histone $\mathrm{H} 3$ and $\mathrm{H} 4$ from LA homogenates from vehicle- and 5-AZA-infused rats. (Right) Western blot analysis of total histone H3 and H4 from LA homogenates from vehicle- and 5-AZA-infused rats. Representative blots can be viewed in the inset. $(D)$ Schematic of the behavioral protocol. Rats were trained, followed $24 \mathrm{~h}$ later by auditory fear memory retrieval administered in a distinct context. Immediately after the reactivation, rats were given intra-LA infusion of either TSA ( $1 \mu \mathrm{g}$ in 0.5 $\mu \mathrm{L} /$ side) or vehicle $(0.5 \mu \mathrm{L} /$ side), followed $60 \mathrm{~min}$ later by intra-LA infusion of 5-AZA ( $1 \mu \mathrm{g}$ in $0.5 \mu \mathrm{L} /$ side) or vehicle $(0.5 \mu \mathrm{L} /$ side), creating the following groups: veh-veh $(n=5)$, veh-5-AZA $(n=5)$, and TSA-5-AZA $(n=6)$. PR-LTM was examined $24 \mathrm{~h}$ following the reactivation trial. (E) Post-shock freezing scores in each group immediately after the conditioning trials. $(F)$ Memory reactivation scores in each group during the tone reactivation trial. ${ }^{*} P<0.05$ relative to the preCS period. (G) Auditory fear memory assessed $24 \mathrm{~h}$ after reactivation in each group across all 10 tone presentations. $(H)$ Histological verification of cannula placements for rats infused with vehicle-vehicle (black circles), or vehicle-5-AZA (gray circles), or TSA-5-AZA (white circles). (Panels were adapted from Paxinos and Watson [1998] with permission from Elsevier (C) 1998.)

5-AZA-infused groups revealed a main effect of trial $\left(F_{(1,13)}=\right.$ 613.33, $P<0.05)$, but no significant effect of group $\left(F_{(1,13)}=\right.$ $0.19)$, indicating that both groups exhibited significant and equivalent memory retrieval during the reactivation trial (Fig. 8B). Intra-LA infusion of 5-AZA following fear memory retrieval resulted in significantly reduced histone $\mathrm{H} 3$ acetylation compared to vehicle-infused controls $\left(t_{(13)}=2.40, P<0.05\right)$, yet had no effect on histone $\mathrm{H} 4$ acetylation $\left(t_{(13)}=0.45\right)$ (Fig. 8C, left). Moreover, no differences were observed in the total protein levels of histone $\mathrm{H} 3\left(t_{(13)}=0.28\right), \mathrm{H} 4\left(t_{(13)}=0.25\right)$ (Fig. 8C, right), or in the loading protein GAPDH $\left(t_{(13)}=0.48\right)$ (data not shown).

\section{Inhibition of HDAC activity in the LA rescues the reconsolidation deficit induced by a DNMT inhibitor}

We have shown that intra-LA infusion of the DNMT inhibitor 5-AZA significantly impairs retrieval-related increases in histone H3 acetylation, a finding which suggests that histone acetylation and DNA methylation may work in concert during memory reconsolidation. In a final behavioral experiment, we sought to determine whether infusion of the HDAC inhibitor TSA can rescue the reconsolidation deficit induced by the DNMT inhibitor 5-AZA.

Rats were trained with three tone-shock pairings, followed $24 \mathrm{~h}$ later by auditory fear memory reactivation administered in a distinct context. Rats were immediately infused with either TSA ( $1 \mu \mathrm{g}$ in $0.5 \mu \mathrm{L} /$ side) or vehicle $(0.5 \mu \mathrm{L} /$ side), followed one hour later by infusion of either 5-AZA ( $1 \mu \mathrm{g}$ in $0.5 \mu \mathrm{L} /$ side) or vehicle $(0.5 \mu \mathrm{L} /$ side $)$. All rats were given a PR-LTM test $24 \mathrm{~h}$ later (Fig. 8D). There was no difference in levels of pre- vs. post-shock freezing between the vehicle/vehicle, vehicle-5-AZA, and TSA-5-AZA groups (Fig. 8E). An ANOVA (group by trial) revealed a significant main effect of trial $\left(F_{(3,39)}=558.95, P<0.01\right)$, but no significant main effect of group $\left(F_{(2,13)}=0.02\right)$ or group by trial interaction $\left(F_{(6,39)}=0.86\right)$. Further, on the next day, all three groups showed equivalent levels of freezing during the preCS 
period and the tone-CS presentation during the reactivation trial (Fig. 8F). An ANOVA (group by trial) revealed no significant effect of group $\left(F_{(2,13)}=0.14\right)$ or group by trial interaction $\left(F_{(2,13)}=\right.$ $0.36)$; however, there was a significant main effect of trial $\left(F_{(1,13)}=2425.8, P<0.01\right)$, indicating that there was an increase in freezing to the tone CS relative to the preCS period in each group. The next day, the group infused with vehicle-5-AZA exhibited impaired PR-LTM, while the TSA-vehicle- and vehiclevehicle-infused groups showed equivalent levels of freezing (Fig. 8G). The ANOVA (group by trial) revealed significant main effects of group $\left(F_{(2,13)}=63.27, P<0.01\right)$ and trial $\left(F_{(9,117)}=\right.$ $7.75, P<0.01)$, but no significant group by trial interaction $\left(F_{(18,117)}=1.11\right)$. Duncan's post-hoc tests for the significant main effect of group revealed that the vehicle-5-AZA-infused group exhibited significantly less freezing than both the TSA-5AZA and vehicle-vehicle groups $(P<0.05)$, which were not found to be significantly different. Thus, these findings both confirm that intra-LA infusion of a DNMT inhibitor interferes with PR-LTM and also indicate that pretreatment with an HDAC inhibitor can rescue the reconsolidation deficit induced by a DNMT inhibitor. Cannula placements are shown in Figure 8H.

\section{Discussion}

The study of the molecular mechanisms underlying fear memory reconsolidation has progressed rapidly in recent years (Dudai and Eisenberg 2004; Alberini 2005; Tronson and Taylor 2007), fueled in part by the promise of discovering novel pharmacological approaches for the treatment of fear-based psychiatric disorders. While most studies have focused on the involvement of intracellular signaling pathways, transcription factors, and the regulation of specific genes in fear memory reconsolidation processes (Nader et al. 2000; Kida et al. 2002; Duvarci et al. 2005; Lee et al. 2005; Tronson et al. 2006; Duvarci et al. 2008; Maddox and Schafe 2011), it has been suggested that epigenetic mechanisms may also play a critical role (Lubin and Sweatt 2007; Bredy and Barad 2008). Epigenetic alterations, including histone acetylation and DNA methylation, have been extensively studied in both hippocampal- and amygdala-dependent memory paradigms and in regions of the brain associated with drug addiction (Levenson and Sweatt 2005, 2006; Tsankova et al. 2007; Barrett and Wood 2008; Jiang et al. 2008; Renthal and Nestler 2008; Monsey et al. 2011). In the present study, we systemically examined the role of epigenetic alterations in the reconsolidation of an amygdaladependent Pavlovian fear memory. Collectively, our findings indicate that retrieval of an auditory fear memory regulates histone $\mathrm{H} 3$ acetylation in LA neurons and that intra-LA infusion of inhibitors to HDAC and DNMT activity enhance or impair fear memory reconsolidation, respectively.

Post-translational modifications in chromatin structure via histone acetylation have been widely implicated in cellular differentiation and development and, more recently, in synaptic plasticity and memory formation (Levenson and Sweatt 2005; Barrett and Wood 2008; Roth and Sweatt 2009). Unmodified chromatin is considered highly inhibitory to transcription as the result of tight binding of histones to DNA via positively charged lysine residues on the N-terminal tails of histone proteins. Acetylation of histones via HATs neutralizes the positive charge on the lysine residue, relaxing the histone-DNA bond and allowing transcription factors to access DNA (Varga-Weisz and Becker 1998; Turner 2002; Yang and Seto 2007). Acetylation of Lys-14 on histone H3 appears to be particularly important for transcriptional regulation. In the present study, we show that retrieval of an auditory fear memory transiently regulates the acetylation of histone $\mathrm{H} 3$, but not H4, in the LA 90 min following reactivation. Further, our findings suggest that alterations in histone $\mathrm{H} 3$ acetylation are specific to actively retrieved memories and are not attributable to other factors, including context novelty. Further, intra-LA infusion of the HDAC inhibitor TSA $1 \mathrm{~h}$ following auditory fear memory retrieval was observed to significantly enhance fear memory reconsolidation; that is, PR-LTM is enhanced, while PR-STM is unaffected. This enhancement was observed to be specific to reactivated memories and to be temporally constrained; there was no effect of HDAC inhibition in the absence of memory reactivation or following delayed infusion. These findings extend those of a recent study showing that infusion of the HDAC inhibitor sodium butyrate $(\mathrm{NaB})$ can rescue the contextual fear reconsolidation deficit induced by IkB inhibition in the hippocampus (Lubin and Sweatt 2007), and provide strong evidence that modification of chromatin structure via histone acetylation plays an important role in amygdala-dependent memory reconsolidation processes.

While previous studies have implicated alterations in DNA methylation in hippocampal- and amygdala-dependent memory consolidation (Miller and Sweatt 2007; Miller et al. 2008; Monsey et al. 2011), no study has to date examined the role of DNA methylation in reconsolidation processes. The methylation of cytosine residues on DNA is typically thought to negatively regulate transcription via preventing the binding of transcription factors (Levenson and Sweatt 2005; Levenson et al. 2006; Miller and Sweatt 2007; Miller et al. 2008). In development, this process has been associated with gene silencing and cellular differentiation, and is believed to be a long-lasting, static process (Levenson and Sweatt 2005; Miranda and Jones 2007). Neurons, however, are known to express high levels of DNMT mRNA into adulthood, suggesting that dynamic regulation of DNA methylation may be critical for neuronal function, including synaptic plasticity and memory formation (Goto et al. 1994; Feng et al. 2010). In our experiments, we show that inhibition of DNMT activity impairs auditory fear memory reconsolidation; PR-LTM is impaired, while PR-STM is unaffected. Further, consistent with our HDAC inhibitor experiments, we showed that the effect of DNMT inhibition on memory reconsolidation is specific to reactivated memories and temporally graded; there was no effect of DNMT inhibition in the absence of memory reactivation or following delayed infusion. Further, we showed that fear memories that are lost following post-retrieval DNMT inhibition are not subject to spontaneous recovery, to reinstatement following a series of unsignaled foot-shocks, or to a shift in the testing context, all of which are hallmark characteristics of extinguished fear memories (Pavlov 1927; Bouton and Bolles 1979a,b). While our findings of impaired fear memory reconsolidation following treatment with 5-AZA are similar to those observed in previous studies that have used this compound to examine the role of DNA methylation in hippocampal- and amygdala-dependent learning paradigms (Miller and Sweatt 2007; Lubin et al. 2008; Miller et al. 2008, 2010; Monsey et al. 2011), it is worth noting that, outside of the CNS, 5-AZA is considered an S-phase-specific nucleoside analogue that inhibits DNA methylation during DNA replication. Thus, the precise mechanism by which 5-AZA works in post-mitotic cells of the CNS is presently unknown. However, several studies have shown that 5-AZA can effectively modulate DNA methylation in the hippocampus (Miller and Sweatt 2007) and prefrontal cortex (Miller et al. 2010). Further, in our experiments we showed that the nonnucleoside DNMT inhibitor RG108 results in a similar retrieval-dependent auditory fear memory reconsolidation deficit. Additional experiments will be required to determine how both 5-AZA and RG108 are affecting the methylation of genes in the LA following retrieval of a fear memory.

Given that DNA methylation is thought to negatively regulate transcription, the finding that DNMT inhibition in the LA impairs memory reconsolidation is somewhat paradoxical. Our findings, however, suggest that intra-LA infusion of 5-AZA not 
only impairs fear memory reconsolidation but also significantly attenuates the retrieval-related increase in histone $\mathrm{H} 3$ acetylation following memory reactivation. Further, pretreatment with the HDAC inhibitor, TSA, was observed to completely reverse the 5-AZA-induced reconsolidation impairment in the LA. These findings are consistent with those of previous studies that have demonstrated that DNMT inhibition may regulate memory formation and synaptic plasticity by influencing histone acetylation (Miller et al. 2008; Roth and Sweatt 2009) and are the first to suggest that histone acetylation and DNA methylation interact to regulate memory reconsolidation processes in the LA.

In summary, the results of the present work provide strong evidence that histone acetylation and DNA methylation regulate auditory fear memory reconsolidation within the LA. These findings are the first of which we are aware to systematically examine the role of epigenetic mechanisms in amygdala-dependent reconsolidation processes and further contribute to our understanding of the cellular and molecular mechanisms of fear memory reconsolidation within the LA.

\section{Materials and Methods}

\section{Subjects}

Adult-male Sprague-Dawley rats (Harlan), weighing 300-350 g and age $2-3 \mathrm{mo}$, were housed individually in plastic cages and maintained on a 12:12 h light/dark cycle with food and water provided ad libitum.

\section{Surgery}

Rats were anesthetized with i.p. administration of Ketamine $(100 \mathrm{mg} / \mathrm{kg})$ and Xylazine $(6.0 \mathrm{mg} / \mathrm{kg})$ and implanted with $26-$ gauge stainless-steel guide cannulas (Plastics One) in the LA $(-3.2 \mathrm{~mm}, \pm 5.2 \mathrm{~mm},-8.0 \mathrm{~mm}$ relative to Bregma). Guide cannulas were secured to screws in the skull using a mixture of dental acrylic and cement, and 31-gauge dummy cannulas were inserted into the guide to prevent obstruction. Buprenex $(0.2 \mathrm{mg} / \mathrm{kg})$ was administered as an analgesic, and rats were provided with at least $5 \mathrm{~d}$ post-operative recovery time. All surgical procedures were conducted under the guidelines provided in the National Institutes of Health Guide for the Care and Use of Experimental Rats and were approved by the Yale University Institutional Animal Care and Use Committee.

\section{Drugs}

The DNA methyltransferase inhibitors 5-AZA-2'- deoxycytidine (5-AZA; Sigma Cat\# A3656), N-Phthalyl-L-Tryptophan (RG108; Sigma Cat\# R8279), and the histone deacetylase inhibitor Trichostatin-A (TSA; Sigma Cat\# T8552) were dissolved in 100\% DMSO to a $4 \mu \mathrm{g} / \mu \mathrm{L}$ stock solution. All three drugs were then diluted $1: 1$ in ACSF to a final $1 \mu \mathrm{g} / \mu \mathrm{L}$ solution. All vehicle solutions consisted of 50\% DMSO in ACSF.

\section{Memory reactivation and Western blotting experiments}

For Western blotting experiments examining the regulation of histone acetylation in the LA following auditory fear memory retrieval, rats were habituated to handling and to both conditioning and testing chambers (30 $\mathrm{min} /$ day/chamber) for $4 \mathrm{~d}$ prior to auditory fear conditioning consisting of three tone-shock pairings (30 sec, $5 \mathrm{kHz}, 75 \mathrm{~dB}, 1.0 \mathrm{~mA})$. The conditioning chamber (Chamber A) was a lit chamber with a grid floor, while the testing chamber (Chamber B) was dark and contained a black plastic floor that had been washed with a distinctive peppermint soap (Schafe et al. 1999). Twenty-four hours following conditioning, rats in the reactivation group were placed in Chamber $B$ and presented with $a$ single tone CS (30 sec, $5 \mathrm{kHz}, 75 \mathrm{~dB}$ ). Rats in the no-reactivation group were placed in Chamber B for the same amount of time as those in the reactivation group but were not presented with a tone reactivation trial. Sixty, 90, or 120 min following the reactivation (or no-reactivation) session, rats were rapidly and deeply anesthetized with chloral hydrate $(600 \mathrm{mg} / \mathrm{kg}$, i.p.), and brains were removed and frozen at $-80^{\circ} \mathrm{C}$ until processed. Naive rats were handled but not exposed to either Chamber A or B prior to sacrifice.

Punches containing the LA were obtained with a 1-mm punch tool (Fine Science Tools) from $400-\mu \mathrm{m}$-thick sections taken on a sliding freezing microtome. Punches were manually dounced in $100 \mu \mathrm{L}$ of ice-cold hypotonic lysis buffer [10 mM Tris- $\mathrm{HCl}, \mathrm{pH}$ 7.5, $1 \mathrm{mM}$ EDTA, $2.5 \mathrm{mM}$ sodium pyrophosphate, $1 \mathrm{mM}$ phenylmethylsulfonyl fluoride, $1 \mathrm{mM} \beta$-glycerophosphate, $1 \%$ Igepal CA-630, 1\% protease inhibitor cocktail (Sigma) and $1 \mathrm{mM}$ sodium orthovanadate]. Sample buffer was immediately added to the homogenates, and the samples were boiled for $4 \mathrm{~min}$. Homogenates were electrophoresed on $18 \%$ Tris- $\mathrm{HCl}$ gels and blotted to Immobilon-P (Millipore). Western blots were then blocked in TTBS buffer (50 mM Tris- $\mathrm{HCl}, \mathrm{pH} 7.5,150 \mathrm{mM} \mathrm{NaCl}$, and $0.05 \%$ Tween-20) with 5\% dry milk and then incubated with the appropriate primary antibody [AcH3 (Lys 9/14), 1:3000, Millipore; AcH4 (Lys9), 1:5000, Millipore; total H3, 1:5000, Millipore; total H4, 1:5000, Millipore]. Blots were then incubated with anti-rabbit antibody conjugated to horseradish peroxidase (Cell Signaling) and developed using West Dura chemiluminescent substrate (Pierce Laboratories). Western blots were developed in the linear range used for densitometry. Densitometry was conducted using Image J software. To control for inconsistencies in loading, optical densities for total histone protein were normalized to GAPDH protein (1:20,000; Abcam). Acetyl-histone proteins were then normalized to total-histone protein, and finally, data were normalized to the average value of naive controls, and analyzed using ANOVA.

\section{Behavioral experiments}

Rats were handled for $2 \mathrm{~d}$ prior to conditioning. On the second handling day, dummy cannulas were removed to check for patency. Rats were then habituated to Chamber A for 15 min (Day 1). The following day (Day 2), rats were placed in Chamber $\mathrm{A}$ and presented with either three tone-shock pairings consisting of a $30 \mathrm{sec}, 5 \mathrm{kHz}, 75 \mathrm{~dB}$ tone that coterminated with a $1 \mathrm{sec}$, $1.0 \mathrm{~mA}$ foot shock (for 5-AZA and RG108 experiments), or two tone-shock pairings, consisting of a $30 \mathrm{sec}, 5 \mathrm{kHz}, 75 \mathrm{~dB}$ tone that coterminated with a $1 \mathrm{sec}, 0.5 \mathrm{~mA}$ foot shock (for TSA experiments). This slightly weaker training protocol was used in the TSA experiments to avoid a ceiling effect which might interfere with observation of the memory enhancing effects of TSA. The next day (Day 3), rats were placed in Chamber B and received either a single tone presentation, to serve as a memory reactivation trial, or no tone presentation, to serve as a no-reactivation trial. One hour following the reactivation or no-reactivation trials, rats received intra-LA infusion of either 5-AZA ( $1 \mu \mathrm{g}$ in $0.5 \mu \mathrm{L} /$ side), RG108 ( $1 \mu \mathrm{g}$ in $0.5 \mu \mathrm{L} /$ side), TSA ( $1 \mu \mathrm{g}$ in $0.5 \mu \mathrm{L} /$ side), or vehicle $(0.5 \mu \mathrm{L} / \mathrm{side})$. Infusions were made over $4 \mathrm{~min}$, and the infusion cannulas were left in place for at least 2 min following infusion to facilitate diffusion throughout the LA. For those groups in which post-reactivation short-term memory (PR-STM) was examined, rats were returned to Chamber B three hours after infusion and tested for PR-STM consisting of the presentation of three tones $(30 \mathrm{sec}, 5 \mathrm{kHz}, 75 \mathrm{~dB})$. Separate groups of rats were tested for post-reactivation long-term memory (PR-LTM). For that test, rats were returned to Chamber $\mathrm{B} \sim 24 \mathrm{~h}$ after memory reactivation and infusion (Day 4) and presented with 10 tones $(30 \mathrm{sec}, 5 \mathrm{kHz}$, $75 \mathrm{~dB})$.

In a separate behavioral experiment, we examined the ability of the HDAC inhibitor TSA to rescue the reconsolidation deficit induced by the DNMT inhibitor 5-AZA. Rats were trained in Chamber A with three tone-shock pairings consisting of a 30 sec, $5 \mathrm{kHz}, 75 \mathrm{~dB}$ tone that coterminated with a $1 \mathrm{sec}, 1.0 \mathrm{~mA}$ foot shock and given a tone reactivation session the next day in Chamber B. Rats received infusions of either TSA ( $1 \mu \mathrm{g}$ in 0.5 $\mu \mathrm{L} /$ side) or vehicle $(0.5 \mu \mathrm{L} /$ side) immediately following memory reactivation, and either 5 -AZA ( $1 \mu \mathrm{g}$ in $0.5 \mu \mathrm{L} /$ side $)$ or vehicle $(0.5$ 
$\mu \mathrm{L} /$ side) one hr later. Rats were then tested for PR-LTM in Chamber B the next day.

An additional behavioral experiment examined whether the reconsolidation deficit induced by DNMT inhibition in the LA was sensitive to spontaneous recovery, reinstatement, or to a shift in the testing context. Rats in this experiment were trained in Chamber A and reactivated $24 \mathrm{~h}$ later in Chamber B and given intra-LA infusions of 5-AZA or vehicle, as described above. Twenty-four hours after reactivation, rats were returned to Chamber B and tested for PR-LTM, as described above. One week after the initial PR-LTM test, rats were returned to Chamber B and tested for spontaneous recovery with five tone presentations. The next day, they were placed in a novel context (Chamber C), scented with cedar and brightly illuminated, and given a reinstatement session consisting of three unsignaled footshocks ( $1 \mathrm{sec}, 1.0 \mathrm{~mA}$ ). Twenty-four hours later, all rats were returned to Chamber B and tested for reinstatement with five tone presentations. The next day, rats were introduced to a final novel context (Chamber D), consisting of a lit behavior box with a scented cotton-padded floor, and tested with three tone presentations to examine the context generality of the reconsolidation deficit.

All behavioral testing was videotaped for subsequent scoring. Freezing was defined as a lack of movement, excluding that necessary for respiration, and was quantified as a percentage of the amount of time the rat spent engaged in freezing behavior during the CS presentations. All data were analyzed with ANOVA and Duncan's post-hoc t-tests. Repeated measures ANOVAs were used for multiple trial comparisons. Differences were considered significant if $P<0.05$. Only data from those rats with bilateral LA placed cannulas were included in the analyses.

\section{Pharmacology and Western blotting experiments}

For Western blotting experiments examining the effect of infusions of 5-AZA or TSA on retrieval-induced changes in histone acetylation, cannulated rats were handled and habituated to Chambers A and B under the aforementioned parameters. On the third day, they were given tone-shock pairings in Chamber A. Rats infused with 5-AZA received three tone-shock pairings consisting of a $30 \mathrm{sec}, 5 \mathrm{kHz}, 75 \mathrm{~dB}$ tone which coterminated with a $1 \mathrm{sec}, 1.0 \mathrm{~mA}$ foot shock, whereas those rats receiving TSA received two tone-shock pairings consisting of a 30 sec, $5 \mathrm{kHz}, 75 \mathrm{~dB}$ tone coterminating with a $0.5 \mathrm{~mA}$ shock. The next day, rats were given an auditory fear memory reactivation session consisting of a $30 \mathrm{sec}, 5 \mathrm{kHz}, 75 \mathrm{~dB}$ tone which was administered in Chamber B. One hour later, rats were given intra-LA infusions or either 5-AZA $(1 \mu \mathrm{g} / 1 \mu \mathrm{L} ; 0.5 \mu \mathrm{L} /$ side $)$, TSA $(1 \mu \mathrm{g} / 1 \mu \mathrm{L} ; 0.5$ $\mu \mathrm{L} /$ side), or vehicle infusions. Thirty min later (90 min after the reactivation session), all rats were given an overdose of chloral hydrate $(600 \mathrm{mg} / \mathrm{kg} ;$ i.p.), and brains were removed and frozen at $-80^{\circ} \mathrm{C}$ until processed. Western blotting on punches taken from around the cannula tips in the LA was conducted as previously described to examine $\mathrm{H} 3 / \mathrm{H} 4$ acetylation.

\section{Acknowledgments}

This research was supported by National Institutes of Health Grant MH 073949 (to G.E.S.) and by Yale University. This research was done with Government support under and awarded by the U.S. Department of Defense, Air Force Office of Scientific Research, National Defense Science and Engineering Graduate (NDSEG) Fellowship, 32 CRF 168a, awarded to S.A.M. We thank Melissa S. Monsey for help with Western blotting experiments and Casey S. Watts for assistance with behavior experiments.

\section{References}

Alberini CM. 2005. Mechanisms of memory stabilization: Are consolidation and reconsolidation similar or distinct processes? Trends Neurosci 28: 51-56.

Barrett RM, Wood MA. 2008. Beyond transcription factors: The role of chromatin modifying enzymes in regulating transcription required for memory. Learn Mem 15: 460-467.
Ben Mamou C, Gamache K, Nader K. 2006. NMDA receptors are critical for unleashing consolidated auditory fear memories. Nat Neurosci 9: $1237-1239$.

Bouton ME, Bolles RC. 1979a. Role of conditioned contextual stimuli in reinstatement of extinguished fear. J Exp Psychol Anim Behav Process 5: $368-378$.

Bouton ME, Bolles RC. 1979b. Contextual control of the extinction of conditioned fear. Learn Motiv 10: 445-466.

Bredy TW, Barad M. 2008. The histone deacetylase inhibitor valproic acid enhances acquisition, extinction, and reconsolidation of conditioned fear. Learn Mem 15: 39-45.

Da Silva WC, Bonini JS, Bevilaqua LR, Medina JH, Izquierdo I, Cammarota M. 2008. Inhibition of mRNA synthesis in the hippocampus impairs consolidation and reconsolidation of spatial memory. Hippocampus 18: 29-39.

Dudai Y, Eisenberg M. 2004. Rites of passage of the engram: Reconsolidation and the lingering consolidation hypothesis. Neuron 44: $93-100$.

Duvarci S, Nader K. 2004. Characterization of fear memory reconsolidation. J Neurosci 24: 9269-9275.

Duvarci S, Nader K, LeDoux JE. 2005. Activation of extracellular signal-regulated kinase-mitogen-activated protein kinase cascade in the amygdala is required for memory reconsolidation of auditory fear conditioning. Eur J Neurosci 21: 283-289.

Duvarci S, Nader K, LeDoux JE. 2008. De novo mRNA synthesis is required for both consolidation and reconsolidation of fear memories in the amygdala. Learn Mem 15: 747-755.

Feng J, Zhou Y, Campbell SL, Le T, Li E, Sweatt JD, Silva AJ, Fan G. 2010. Dnmt1 and Dnmt3a maintain DNA methylation and regulate synaptic function in adult forebrain neurons. Nat Neurosci 13: 423-430.

Goto K, Numata M, Komura JI, Ono T, Bestor TH, Kondo H. 1994. Expression of DNA methyltransferase gene in mature and immature neurons as well as proliferating cells in mice. Differentiation 56: 39-44.

Guan JS, Haggarty SJ, Giacometti E, Dannenberg JH, Joseph N, Gao J, Nieland TJ, Zhou Y, Wang X, Mazitschek R, et al. 2009. HDAC2 negatively regulates memory formation and synaptic plasticity. Nature 459: $55-60$.

Han J, Li Y, Wang D, Wei C, Yang X, Sui N. 2010. Effect of 5-aza-2-deoxycytidine microinjecting into hippocampus and prelimbic cortex on acquisition and retrieval of cocaine-induced place preference in C57BL/6 mice. Eur J Pharmacol 642: 93-98.

Jiang Y, Langley B, Lubin FD, Renthal W, Wood MA, Yasui DH, Kumar A, Nestler EJ, Akbarian S, Beckel-Mitchener AC. 2008. Epigenetics in the nervous system. J Neurosci 28: 11753-11759.

Kida S, Josselyn SA, de Ortiz SP, Kogan JH, Chevere I, Masushige S, Silva AJ. 2002. CREB required for the stability of new and reactivated fear memories. Nat Neurosci 5: 348-355.

Lee JL, Di Ciano P, Thomas KL, Everitt BJ. 2005. Disrupting reconsolidation of drug memories reduces cocaine-seeking behavior. Neuron 47: 795-801.

Levenson JM, Sweatt JD. 2005. Epigenetic mechanisms in memory formation. Nat Rev Neurosci 6: 108-118.

Levenson JM, Sweatt JD. 2006. Epigenetic mechanisms: A common theme in vertebrate and invertebrate memory formation. Cell Mol Life Sci 63: 1009-1016.

Levenson JM, O'Riordan KJ, Brown KD, Trinh MA, Molfese DL, Sweatt JD. 2004. Regulation of histone acetylation during memory formation in the hippocampus. J Biol Chem 279: 40545-40559.

Levenson JM, Roth TL, Lubin FD, Miller CA, Huang IC, Desai P, Malone LM, Sweatt JD. 2006. Evidence that DNA (cytosine-5) methyltransferase regulates synaptic plasticity in the hippocampus. J Biol Chem 281: $15763-15773$

Lubin FD, Sweatt JD. 2007. The IkappaB kinase regulates chromatin structure during reconsolidation of conditioned fear memories. Neuron 55: $942-957$.

Lubin FD, Roth TL, Sweatt JD. 2008. Epigenetic regulation of BDNF gene transcription in the consolidation of fear memory. J Neurosci 28: 10576-10586.

Maddox SA, Schafe GE. 2011. The activity-regulated cytoskeletal-associated protein (Arc/Arg3.1) is required for reconsolidation of a Pavlovian fear memory. J Neurosci 31: 7073-7082.

Maddox SA, Monsey MS, Schafe GE. 2011. Early growth response gene 1 (Egr-1) is required for new and reactivated fear memories in the lateral amygdala. Learn Mem 18: 24-38.

Miller CA, Sweatt JD. 2007. Covalent modification of DNA regulates memory formation. Neuron 53: 857-869.

Miller CA, Campbell SL, Sweatt JD. 2008. DNA methylation and histone acetylation work in concert to regulate memory formation and synaptic plasticity. Neurobiol Learn Mem 89: 599-603.

Miller CA, Gavin CF, White JA, Parrish RR, Honasoge A, Yancey CR, Rivera IM, Rubio MD, Rumbaugh G, Sweatt JD. 2010. Cortical DNA methylation maintains remote memory. Nat Neurosci 13: 664-666. 
Milton AL, Lee JL, Butler VJ, Gardner R, Everitt BJ. 2008. Intra-amygdala and systemic antagonism of NMDA receptors prevents the reconsolidation of drug-associated memory and impairs subsequently both novel and previously acquired drug-seeking behaviors. J Neurosci 28: $8230-8237$

Miranda TB, Jones PA. 2007. DNA methylation: The nuts and bolts of repression. J Cell Physiol 213: 384-390.

Monsey MS, Ota KT, Akingbade IF, Hong ES, Schafe GE. 2011. Epigenetic alterations are critical for fear memory consolidation and synaptic plasticity in the lateral amygdala. Plos One 6: e19958. doi: 10.1371/ journal.pone.0019958.

Nader K, Schafe GE, LeDoux JE. 2000. Fear memories require protein synthesis in the amygdala for reconsolidation after retrieval. Nature 406: $722-726$.

Parsons RG, Gafford GM, Baruch DE, Riedner BA, Helmstetter FJ. 2006. Long-term stability of fear memory depends on the synthesis of protein but not mRNA in the amygdala. Eur J Neurosci 23: 1853-1859.

Pavlov IP. 1927. Conditioned Reflexes. Oxford University Press, London.

Paxinos G, Watson C. 1998. The rat brain in stereotaxic coordinates. Academic Press/Elsevier, San Diego, CA.

Renthal W, Nestler EJ. 2008. Epigenetic mechanisms in drug addiction. Trends Mol Med 14: 341-350.

Roth TL, Sweatt JD. 2009. Regulation of chromatin structure in memory formation. Curr Opin Neurobiol 19: 336-342.

Schafe GE, Nadel NV, Sullivan GM, Harris A, LeDoux JE. 1999. Memory consolidation for contextual and auditory fear conditioning is dependent on protein synthesis, PKA, and MAP kinase. Learn Mem 6: 97-110.
Stefanko DP, Barrett RM, Ly AR, Reolon GK, Wood MA. 2009. Modulation of long-term memory for object recognition via HDAC inhibition. Proc Natl Acad Sci 106: 9447-9452.

Tronson NC, Taylor JR. 2007. Molecular mechanisms of memory reconsolidation. Nat Rev Neurosci 8: 262-275.

Tronson NC, Wiseman SL, Olausson P, Taylor JR. 2006. Bidirectional behavioral plasticity of memory reconsolidation depends on amygdalar protein kinase A. Nat Neurosci 9: 167-169.

Tsankova N, Renthal W, Kumar A, Nestler EJ. 2007. Epigenetic regulation in psychiatric disorders. Nat Rev Neurosci 8: 355-367.

Turner BM. 2002. Cellular memory and the histone code. Cell 111: $285-291$.

Varga-Weisz PD, Becker PB. 1998. Chromatin-remodeling factors: Machines that regulate? Curr Opin Cell Biol 10: 346-353.

Vecsey CG, Hawk JD, Lattal KM, Stein JM, Fabian SA, Attner MA, Cabrera SM, McDonough CB, Brindle PK, Abel T, et al. 2007. Histone deacetylase inhibitors enhance memory and synaptic plasticity via CREB:CBP-dependent transcriptional activation. J Neurosci 27: $6128-6140$.

Yang XJ, Seto E. 2007. HATs and HDACs: From structure, function, and regulation to novel strategies for therapy and prevention. Oncogene 26: $5310-5318$.

Zhao Z, Fan L, Frick KM. 2010. Epigenetic alterations regulate estradiol-induced enhancement of memory consolidation. Proc Natl Acad Sci 107: 5605-5610.

Received April 8, 2011; accepted in revised form June 29, 2011. 


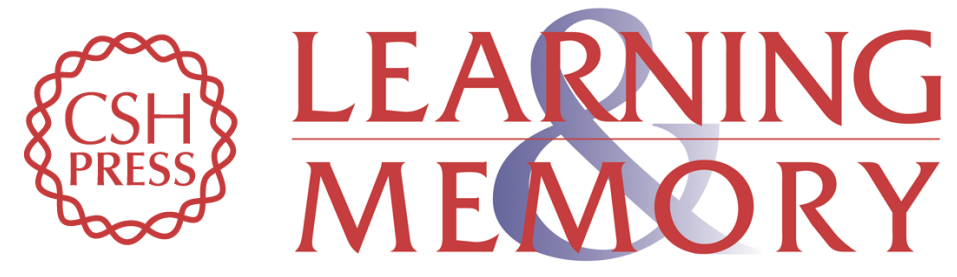

\section{Epigenetic alterations in the lateral amygdala are required for reconsolidation of a Pavlovian fear memory}

Stephanie A. Maddox and Glenn E. Schafe

Learn. Mem. 2011, 18:

Access the most recent version at doi:10.1101/lm.2243411

References This article cites 46 articles, 14 of which can be accessed free at: http://learnmem.cshlp.org/content/18/9/579.full.html\#ref-list-1

License

Email Alerting Receive free email alerts when new articles cite this article - sign up in the box at the Service top right corner of the article or click here. 